\title{
THE MEASUREMENT OF EDUCATIONAL GAB AT THE JORDANIAN BADIA
}

( Received: 13.8. 2007 )

\section{By}

\section{A. Hunaiti and Z. Al- Bashaireh*}

\section{Department of Plant Production, Faculty of Agriculture, * Faculty of Educational Sciences, Mutah University, Karak, Jordan}

\begin{abstract}
This study aims to measure the educational gap at the Jordanian Badia. It aims also to explore the illiteracy reasons, student enrolment and population attitudes towards the school effort at the southern Jordanian Badia and illiteracy reasons compared with educational gap in Jordan. To achieve these goals, 1250 persons have been randomly chosen by a valid and tested questionnaire. Descriptive and analytical statistic was used to measure the factors influencing the educational gap, illiteracy and the enrolment.

The results revealed that there was no statistical difference between the illiteracy and the enrolment level due to the distance between the students house and the school which was found nearly 717 meter. The population attitudes of the southern Badia towards the school performance were not identified. The illiteracy level was estimated 19\% for men and 29\% for women. Although illiteracy level at the Jordanian badia is decreasing, the southern Badia still below the total level (49\%), especially for females ( 53\%) while for males $39 \%$. The illiteracy level concentrated between the age of $40-44$. Sixty two $\%$ of the illiterate persons believe that the main reason was due to work to help the family, while $80 \%$ of females refer that due to get married.

The southern Badia is still below the level in terms of student enrolments in schools. There were statistical differences between the students enrolment due to gender. The enrolment gap at Jordan level $42 \%$ while at the southern Badia $100 \%$. The study also found statistical differences for school enrolment between males and females. Sixty two \% of the females left the school because of getting married while $48 \%$ of males left the school for work. Early statistical differences were found between the educational level and gender. Females were less than males in all educational level. The educational gap was $61 \%$ at the basic cycle and $51 \%$ at secondary and higher education level.
\end{abstract}

Key words: educational gap, rural development, rural education, rural poverty.

$$
\begin{aligned}
& \text { قياس الفجوة التعليمية في البادية الأردنية } \\
& \text { دوخي عبد الرحيم الحنيطي- زيد علي البشايره* } \\
& \text { قسم الانتاج النباتى ـكلية الزر اعة، *كلية العلوم التربوية، جامعة مؤتة_الكرك ـ الأردن ن }
\end{aligned}
$$

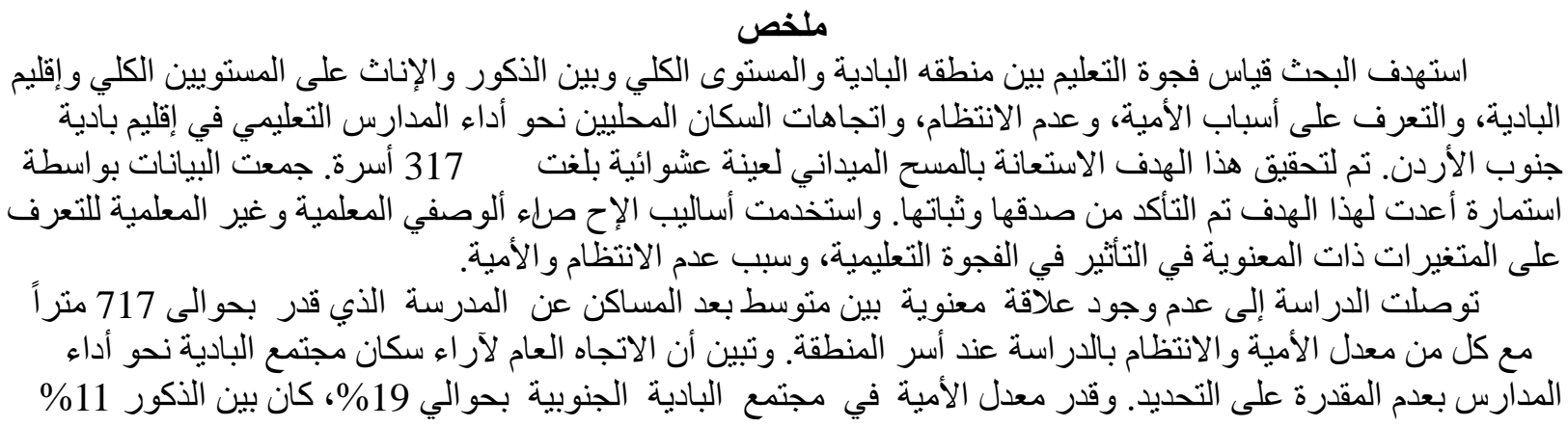


تقريباً، وبين الإناث 29\% تقريباً. وبالر غم من أن نسبة الأمية آخذة في الانخفاض في البادية الأردنية، إلا أن منطقة البادية

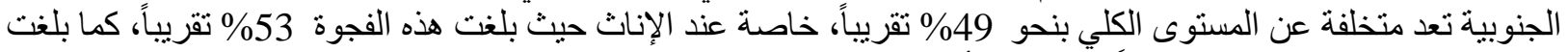

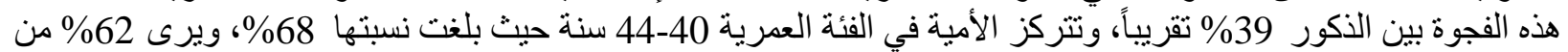

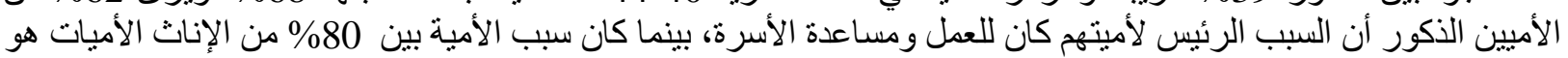

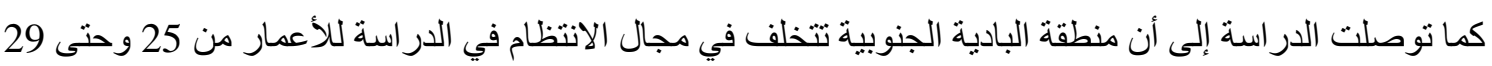
للزواج.

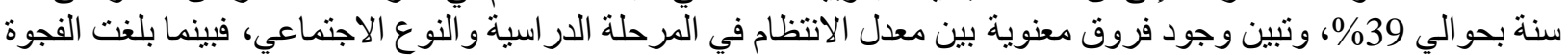

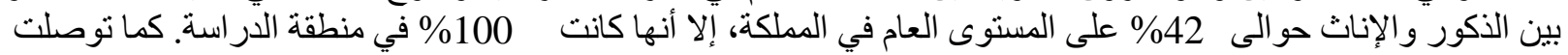

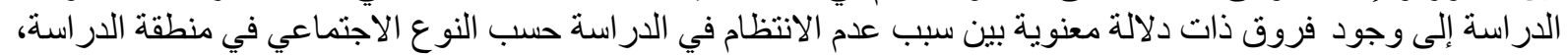

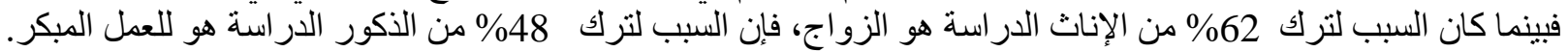

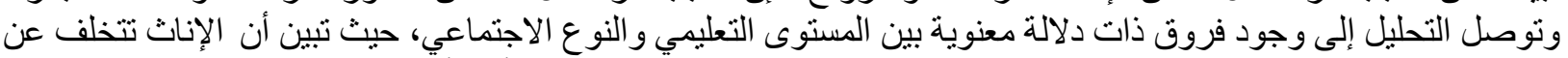

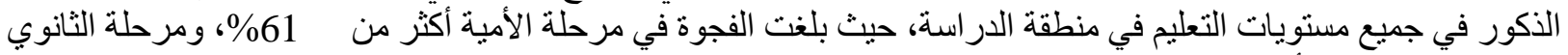

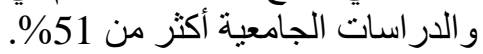

بينما عالج الفكر التنموي في السبعينات مسألثين

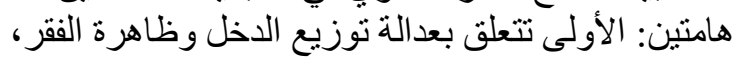

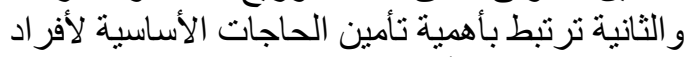

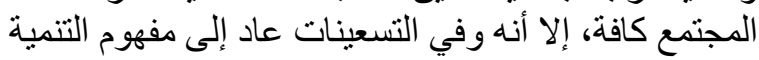

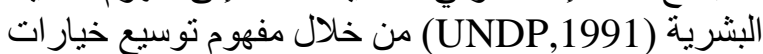

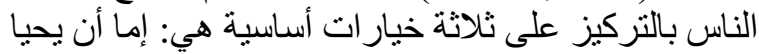

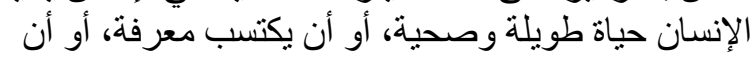

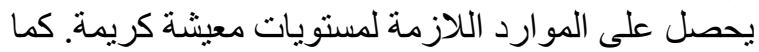

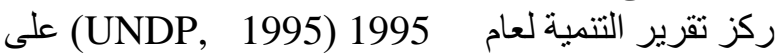

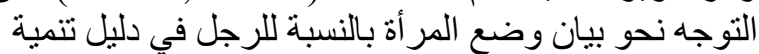

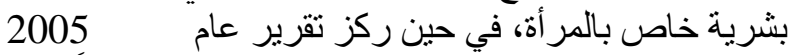

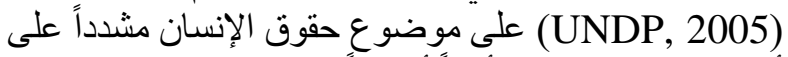

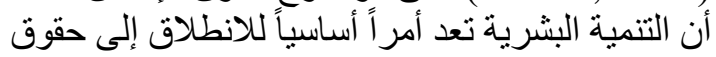

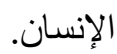

ومن خلال ماورد سابقاً فإن التنمية في المجتمعات

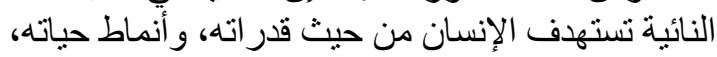

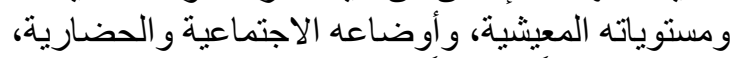

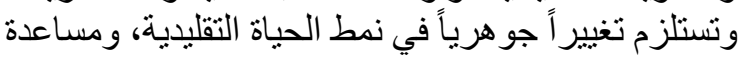

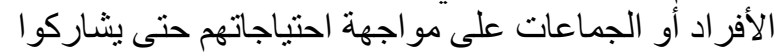

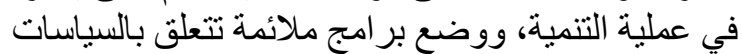

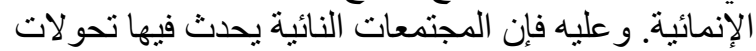

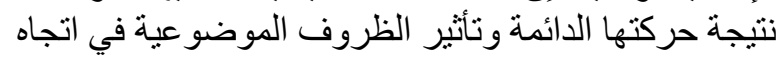

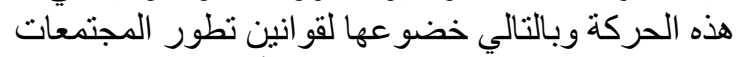

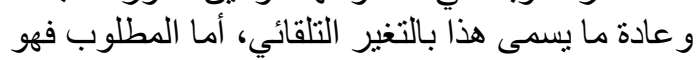

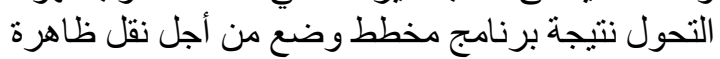

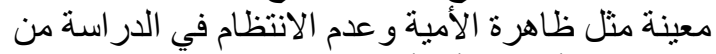

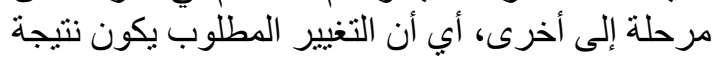

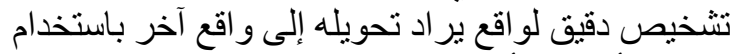

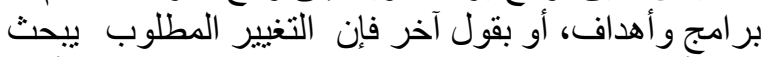

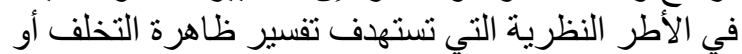

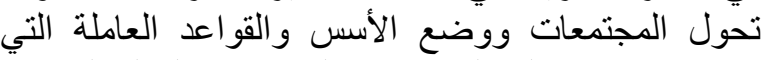

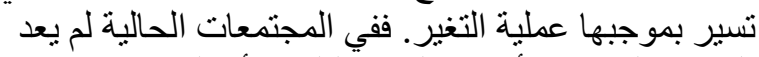

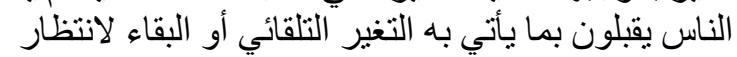

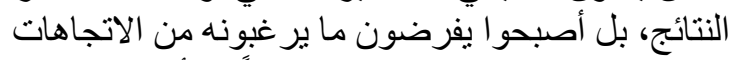

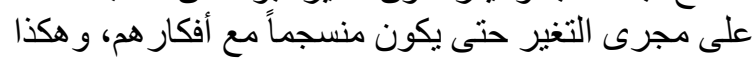

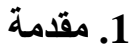

إن الهدف الأساسي من التنمية الريفية هو تقليل

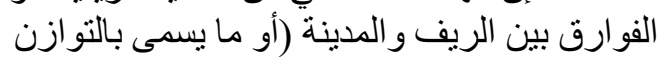

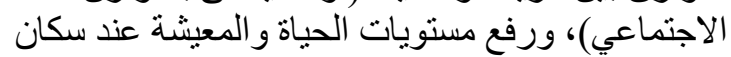
الريف و البادية لتقترب من المستوى الحضري الحئي

(Copp, 1972)

وقد تعددت مظاهر التخلف في المجتمعات النائية، حيث

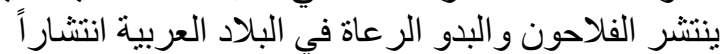

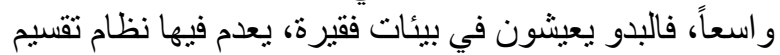

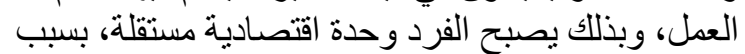

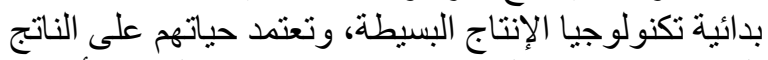

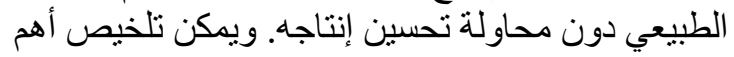
بعض مظاهر التخلف في المجتمعات النائية التي تطرقت التهات

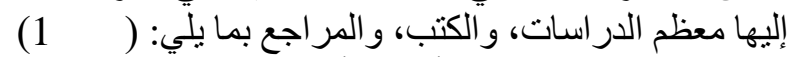

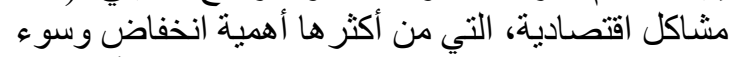

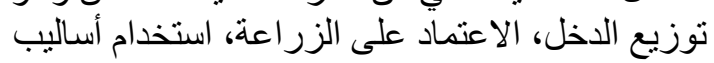

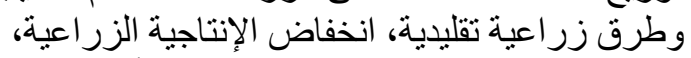

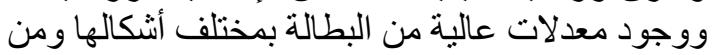

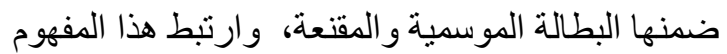

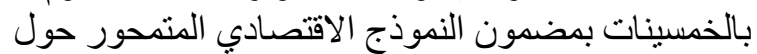

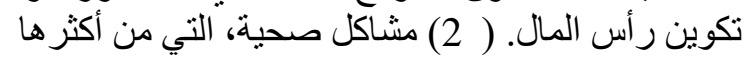

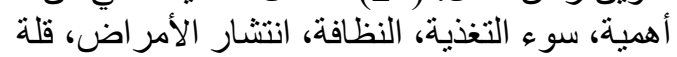

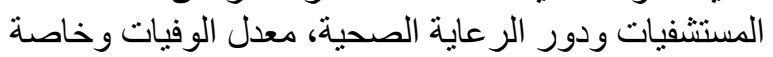

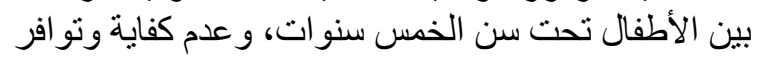

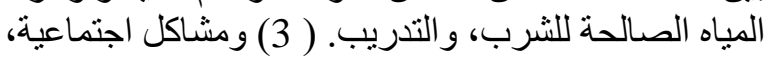

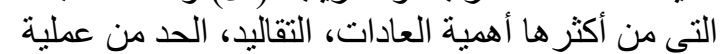

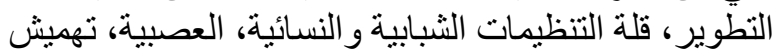

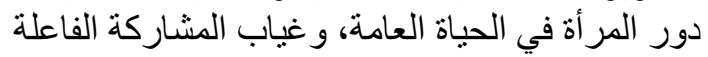

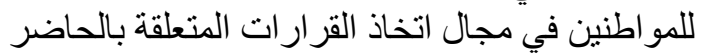

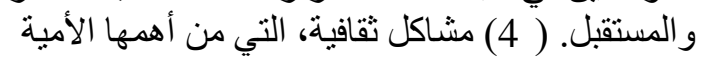

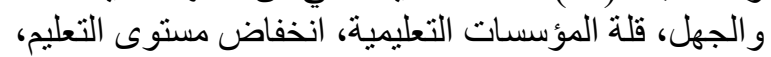

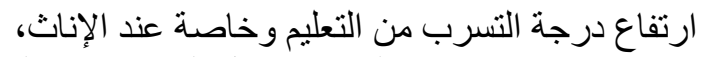

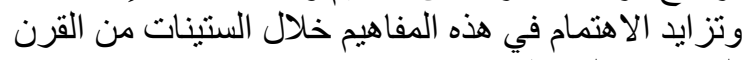
العشرين (الحنيطي، 1997) هذهي الاهئ 
المسئولة عن التعليم لحين صدور قانون المعارف رقم 20 إستر لعام 1955، حيث تم تغيير ها إلى اسم وزارة التئن التربية و التعليم عام 1956. وفي عقد الستينات بدأ الاهتمام بالمناهج و الأهداف (الطو اهيا و الحو امدة، 1998).

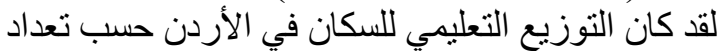

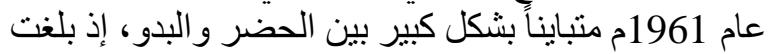

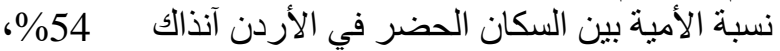

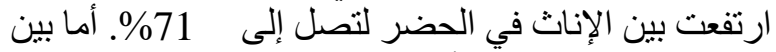
السكان البدو فإن نسبة الأمية كانت بالغة الارتفات الإنفاع حيث شكلت 96.2\% ووصلت إلى نى 99.9\% بين الإنات البدويات في ذلك الوقت (دائرة الإحصاءات العامة العامة،

يعكس ترد واضح في الاهتمام بالمستوى التعلئيمي في الإني

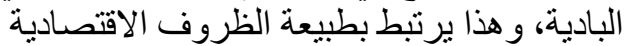

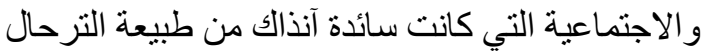

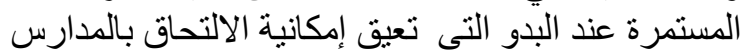

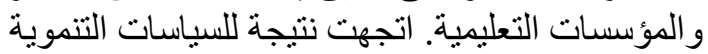

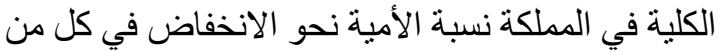

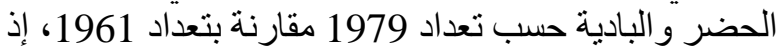

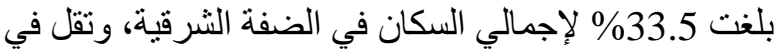

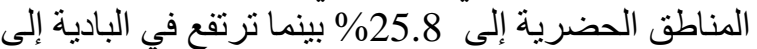

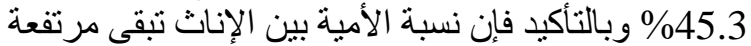
إذ بلغت \%3.4\% و ولكنها تعد منخفضة مقارنة بنتائج تعداد

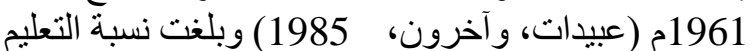

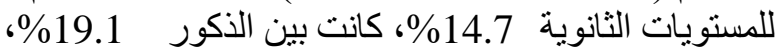

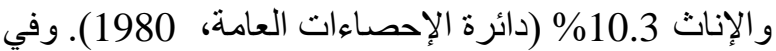
عام 1989 أجرت وزارة الترائ التخطيط در اسة حول تنمية البادية

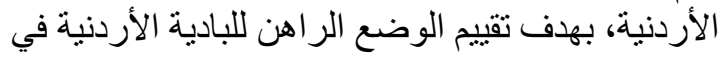

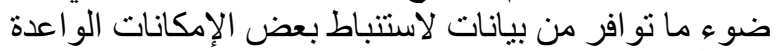

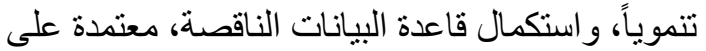

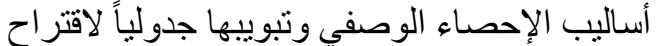
التوصيات الكفيلة بتحقيق تنمية تنفع معظم سكان الإنيان البادية،

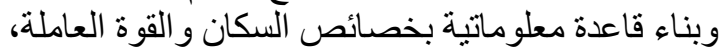

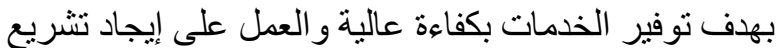
لتوطين البدو ، للمحافظة على بقاء الأيدي العاملة في الإنتاج

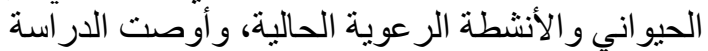

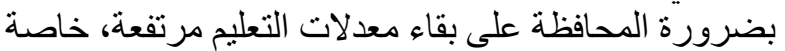

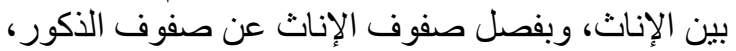
و إنشاء مساكن للمعلمين، وتوفير وسائل نقل للإن للمدارس. وفي تعداد عام 1994 تبين أن نسبة الأمية في الأردن قد انخفضت بشكل ملحوظ خلال الفترة الممتدة بين التعداد الأن

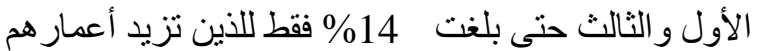

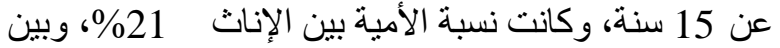

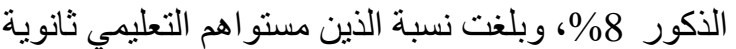

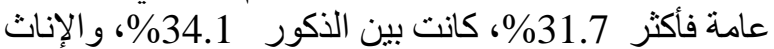

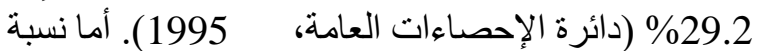

الأمية حسب در اسة البادية الجنوبية التي أجرنها وز الارة

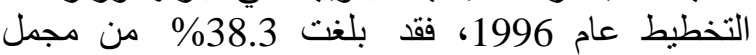
السكان الذين تزيد أعمار هم عن 15 سنة، و63\%؛
ظهر ما يعرف بالتخطيط الاجتماعي، واستطاع الإنسان أن أن إني

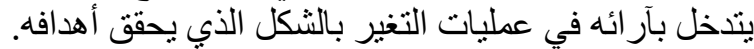

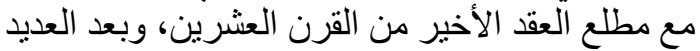

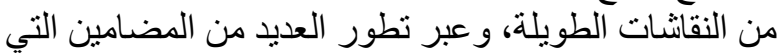

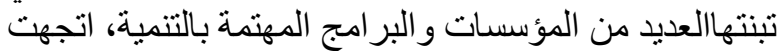

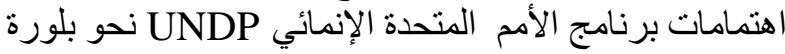

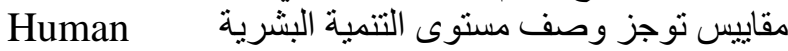
وDevelopment

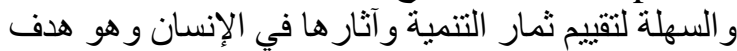
التنمية و غايتها. ومن الاتجاهات التي تحدد مؤشر ات ظاهية التهرة

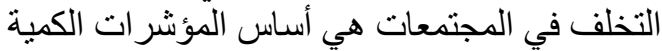

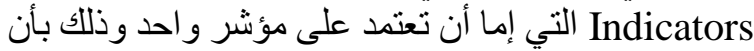

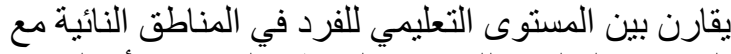

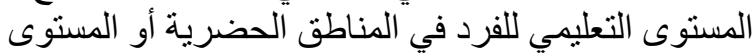

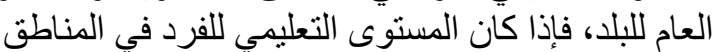

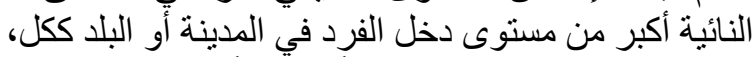

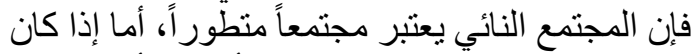

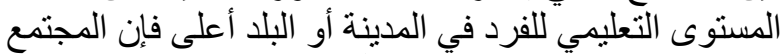

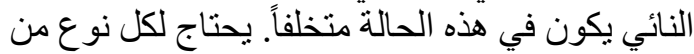

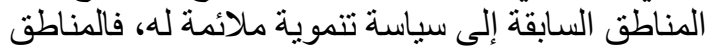

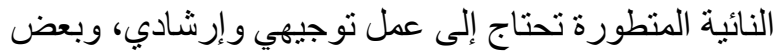

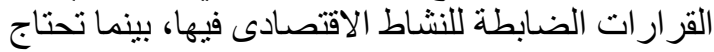

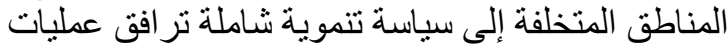

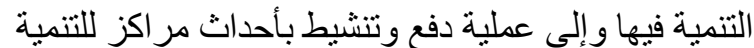

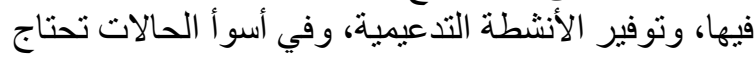

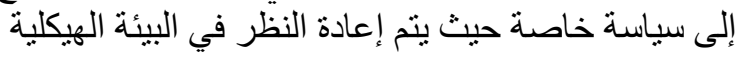

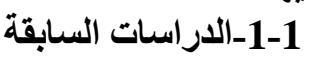

شهذ الأردن منذ نشأته عام 1921م 1921 وحتى اليوم نهضية تعليمية متميزة. فبالر غم من قلة الإمكانيات و افتقار المو المارد

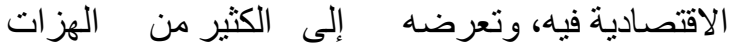

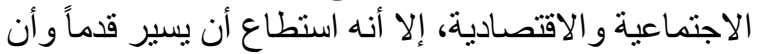
يحتل مكانة رفيعة بين البلدان العربية، على الإنى مستوى إقليم الإنيم الريفو البادية الأردنية، حيث الوالتانية أولت الحكومات الأردنية

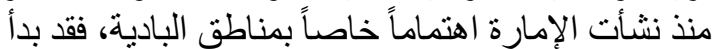

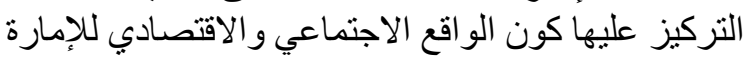

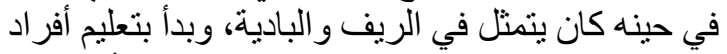

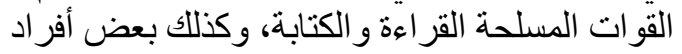

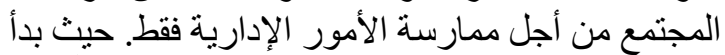
التعليم بالتطور ولكن بيطيء إذ كان التعليم عشو ائياً،

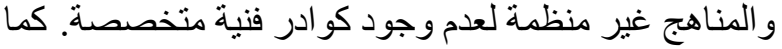

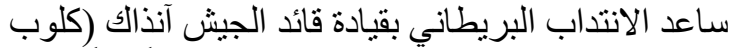

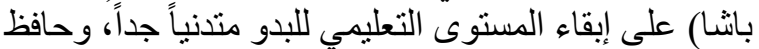
على نسبة عالية من الأمية بين أبناء البدو ، ولم ينت إنشاء البناء

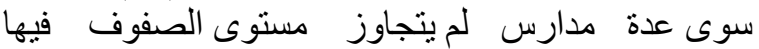

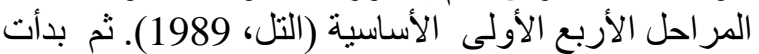
الإمارة بوضع قانون للتعليم فصدر قانون رقية الأنم

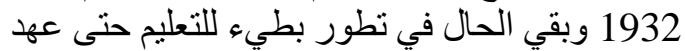
الاستقلال. ومنذ بداية عهد الاستقلال بقيت وزارة المعارف فئ فئ 
الحنيطي ( 2007) في در اسة له عن قياس مستوى نو عية الإن إنية

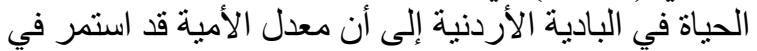

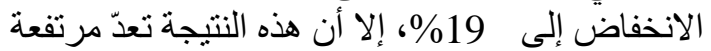

بالمقارنة مع المستوى العام في الأردن والبالغة

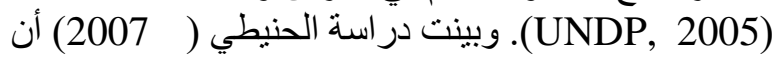

نسبة الالتحاق بكل من المرحلة الابتدائية و المتوسطة ولئة

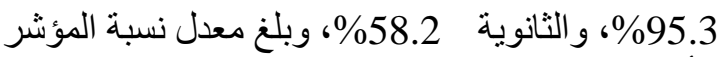

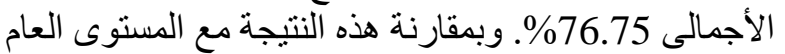

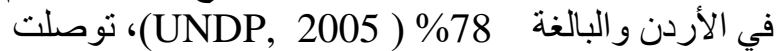

الدراسة إلى تخلف منطقة البادية عن المستوى العام في المملكة من حيث المسنوى التعليمي.

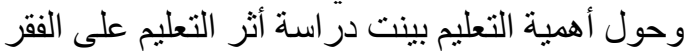

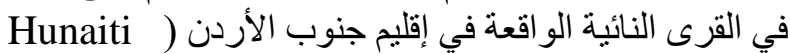

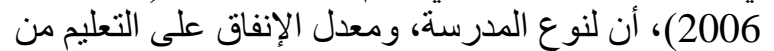

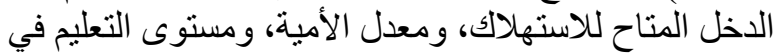

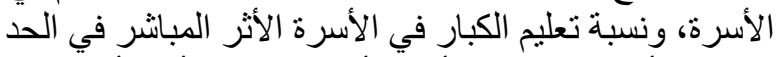

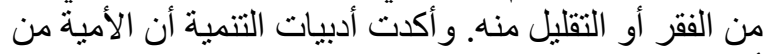

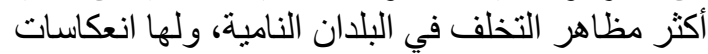

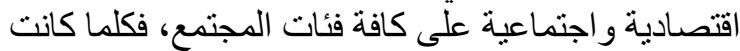

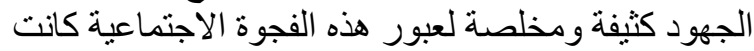

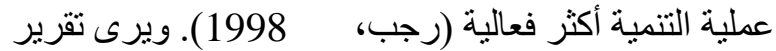

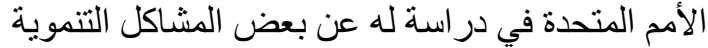

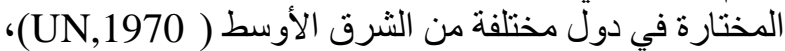

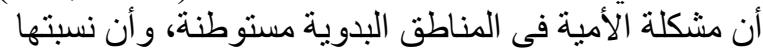
عالية تصل ما بين فأكثر ، وأن الأمية بين البدو ستزداد في المستقبل بسبب العبد العدد

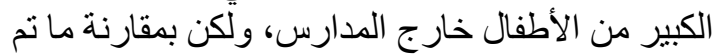

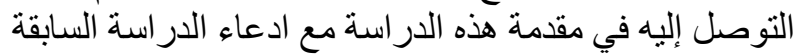

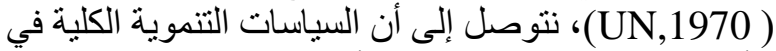
الأردن قد نجحت في الحد من الأمية ورفع مستويات التهاتيات التعليم

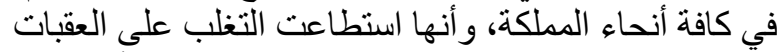

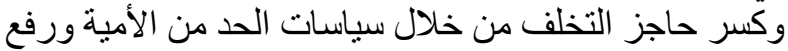
مستويات التعليم في الريف والنين خلبادية.

2-1

تتحدد فرضية البحث الرئيسة بأن منطقة البادية

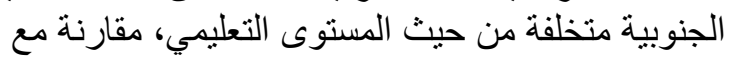

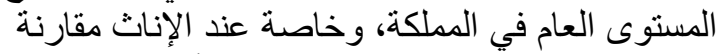

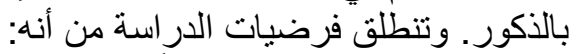

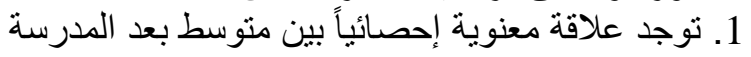

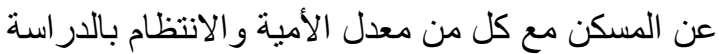
عند أفر اد أسر المنطقة.

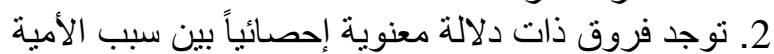

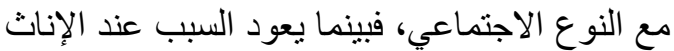
للزواج المبكر، فإنه عند الذكور يعود للعمل والعناية الإنية بمدالح الأسرة.

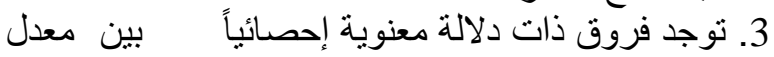

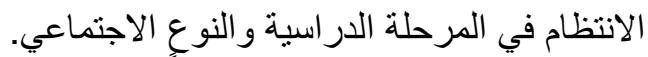

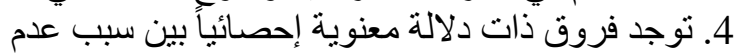
الانتظام في الدراسة حسب دلاندة معند النوع الاجتماعي في منطقة

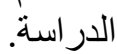

و\%37، لكل من الإناث و الذكور على الترتيب (وزارة

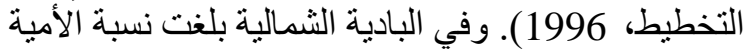

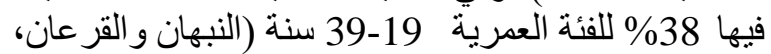

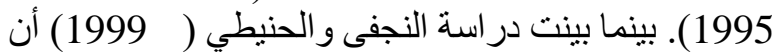

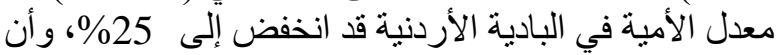

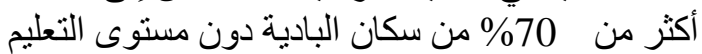

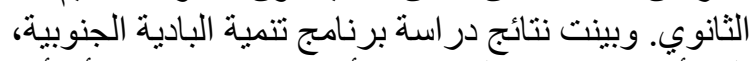

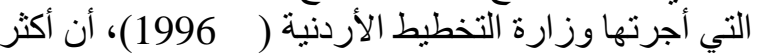

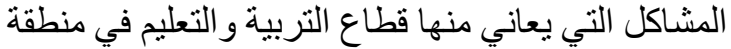

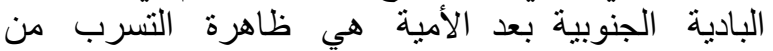
الدراسة، مبينة أن أعداد الطلاب يتناقص بشئ بشكل ملحوظ

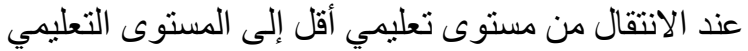

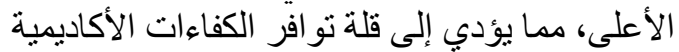

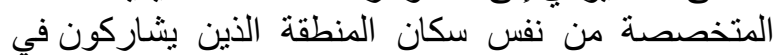
دفع عجلة التنمية و التطوير لدى مجتمعان التهم المحلية.

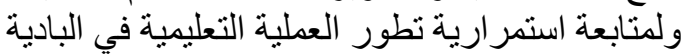

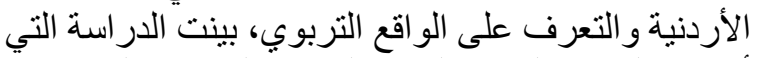

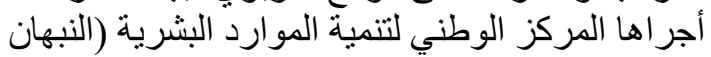

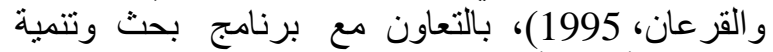
البادية الأردنية أن 60 \% بالنعارن من المدارس في المنطقة المختلطة، كان 90\% منها في المرحلة الأساسية، و

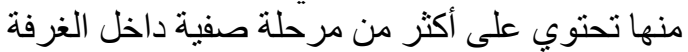
الواحدة، في حين شكلت المدارس الثانوية في مئن

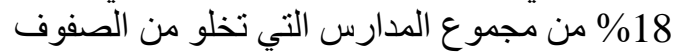

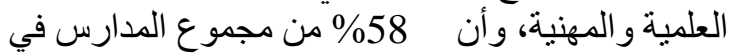

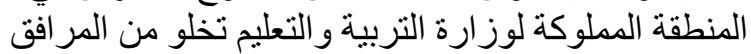

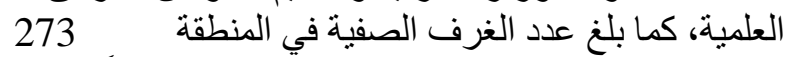
غرفة، ومتوسط حجم المدرسة الواحدة 77 الوفة طالباً بكثافة صفية 14 طالباً في الثعبة الو احدة، ويتراوح عدال عدد الطلبة لكل معلم من ( 11:1) ومعدل الالتحاق بالتعليم 65.3\% \%

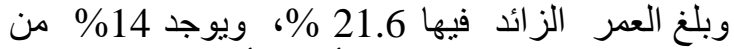

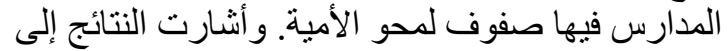

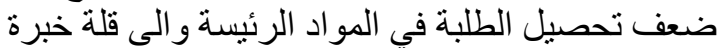

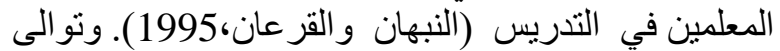

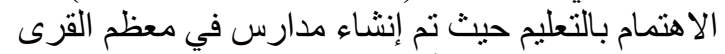

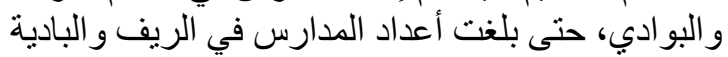

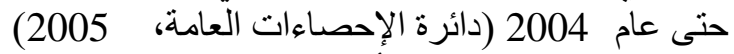

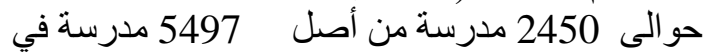
المملكة، وبلغ عدد الثعب الصفية 32200 شعبة من أصل أصل

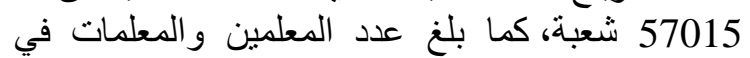
الريف و البادية 35800 معلم ومعلمة من أصل الصل

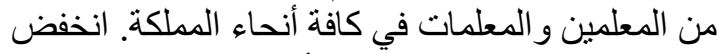

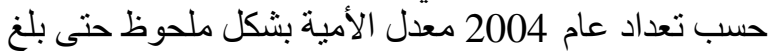

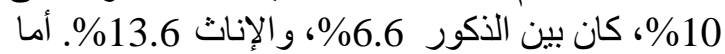

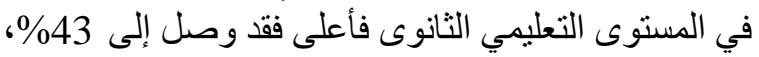

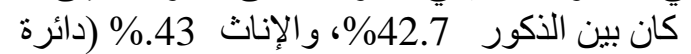

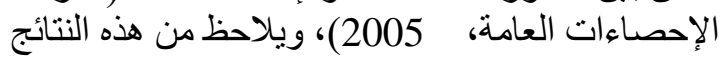

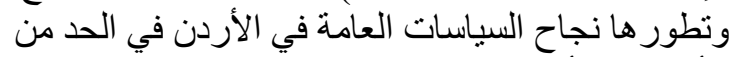
الأمية في الأردن ورفع مستو ليات تعليم الإناث. كما نوصل فل فل فل 


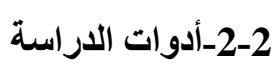

لإنجاز مر احل التحليل ولتحقيق أهداف الدراسة،

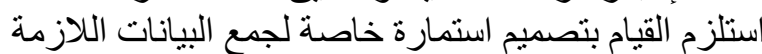

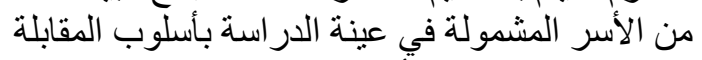

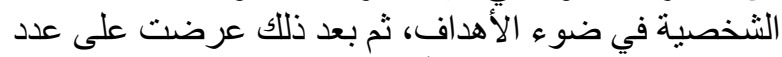

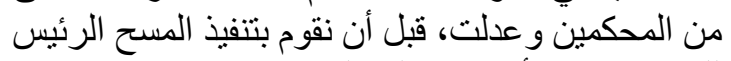

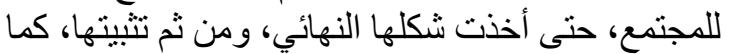

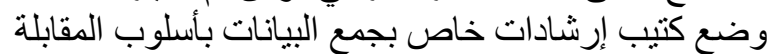

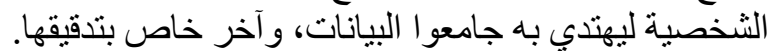

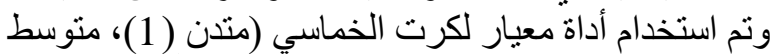

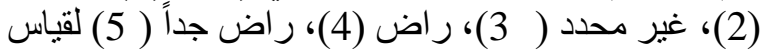

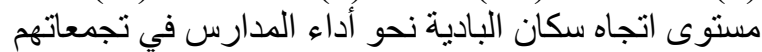
السكنية من حيث الكفاءة والكفاية التيانية التدريسية.

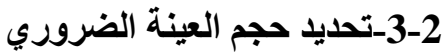

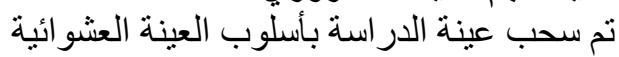

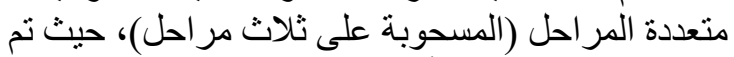

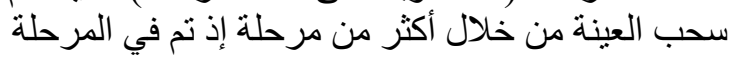
الأولى سحب عينة عشو ائية لعدد الأسر المطلوبة في في في العينة

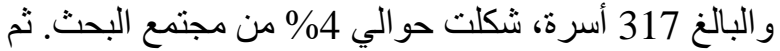

سحبت عينة بلوكات من التجمعات بالطريقة الطيقة العشو ائية.

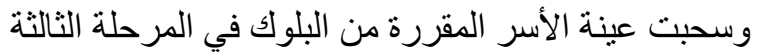
وذللك وفقاً لطريقة العينة العشوائية المنتظمة. والئة واعتمد مبدأ

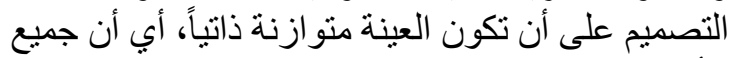

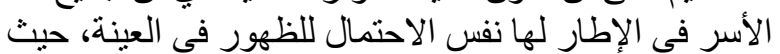

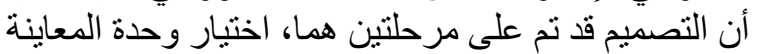
الأولية (البلوك)، ثم اختيار الأسر.
5. توجد فروق ذات دلالة معنوية إحصائياً بين المستوى التعليمي و النوع الاجتماعي. 1-3-1أهداف الاراسة واسئلتها:

تسعى هذه الدر اسة إلى تحقيق الأهداف التالية:

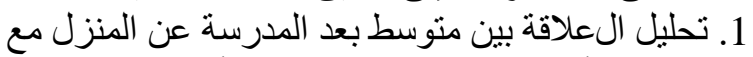

معدل الأمية و الانتظام بالدر اسة عند السئ أسر المنطقة.

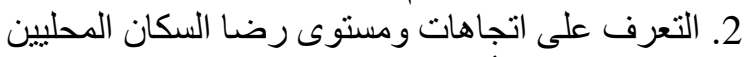

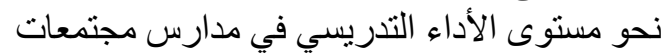
البادية من حيث الكفاءة و الكفاية التدريسية.

3. قياس الفجوة التعليمية لمستوى الأمية، حسب النية الفئات العمرية.

4. التعرف على أسباب الأمية في منطقة الدر اسة و علاقتها بالنوع الاجتماعي.

5. قياس الفجوة التعليمية لمعدل الانتظام في الدر اسة، حسب الإب التبل النوع الاجتماعي، و المرحلة التعليمية.

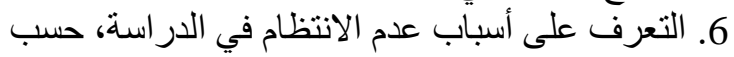
النوع الاجتماعي.

7. قياس الفجوة في الّينوى التئعليمي، حسب النوع

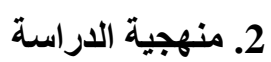

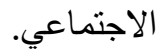

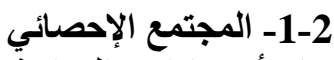

ارتأت إدارة الدراسة تحديد إطار العينة بالمناطق

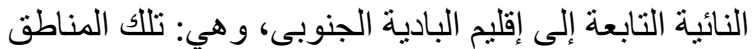

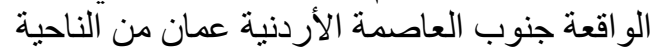

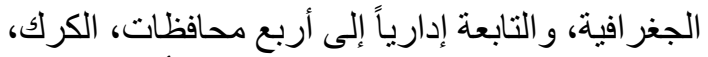

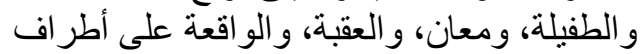

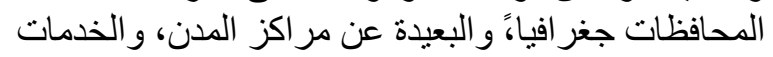

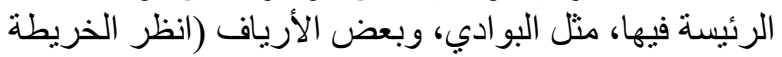

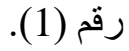
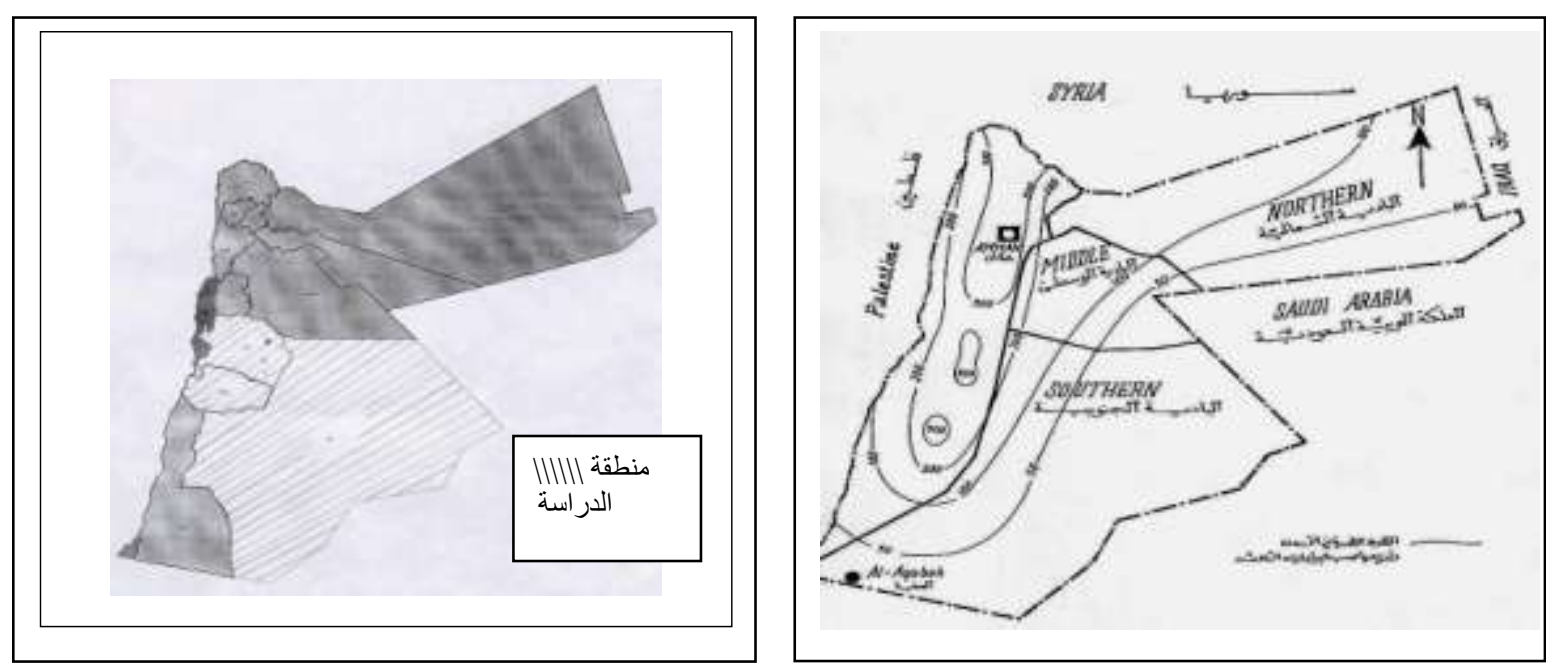

خريطة (1): منطقة الدراسة 
23\% تقريباً، و عليه نستتنج أن وضع منطقة البادية ير عى اهتماماً خاصاً و هو متقدم بالنسبة لهذه الخدمة النية

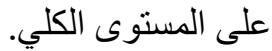

الهلف الأول: تحليل العلاقة بين متوسط بعد المدرسة

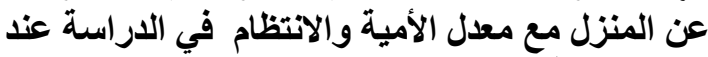
اسر المنطقة.

بين المسح الميداني لمنطقة البادية الجنوبية من المن فئري خلال شكل (2)، أن جميع المناطق يتو افر فئه المئ مدارس. وتبين أن متوسط بعد المدرسة عن المساكن بالمتر

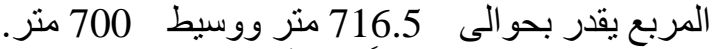
وتعطي هذه النتيجة مؤشر أ على أن خدمة المدارس

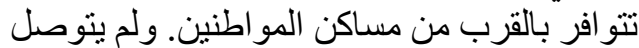

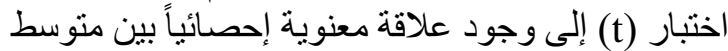

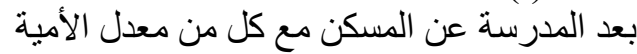
و الانتظام بالدر اسة عند أفر اد أسر المنطقة، مما يعني المنية

عدم قبول الفرضية الصفرية الأولى المدعية بوجية الصود

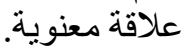

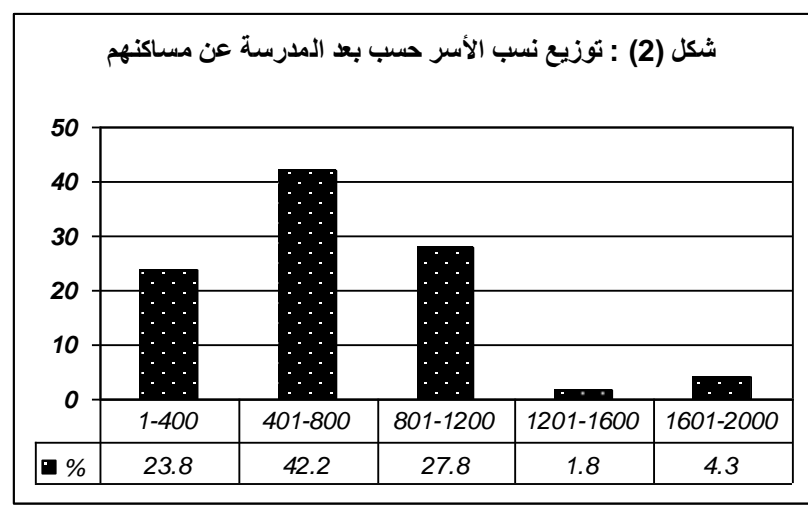

الهذف الثاني: التعرف على اتجاهات ومستوى رضا السكان المحليين نحو مستوى الأداء التدريسي في في مدارس مجتمعات البادية.

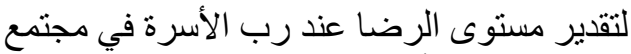

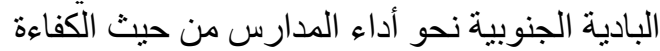

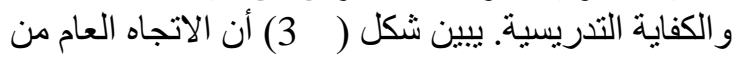
حيث الوسط و الوسيط للآر اء كان بعدم المقدرة على الآنى

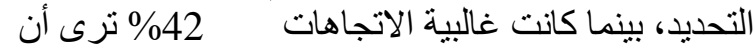

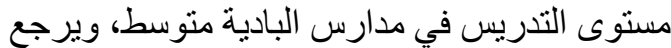

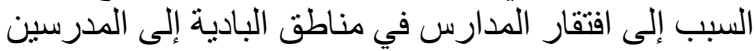

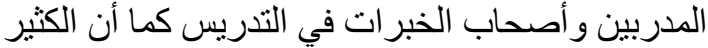

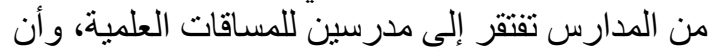

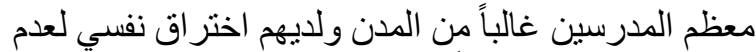

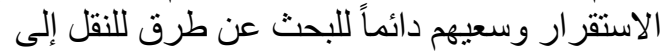

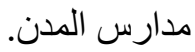

$$
\text { 2-2-أسلوب التحليل }
$$

استعين بيرنامج حزمة البر امج الإحصائية للعلوم

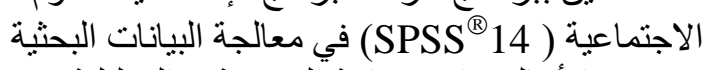

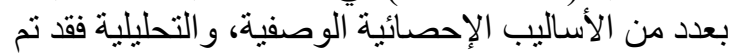

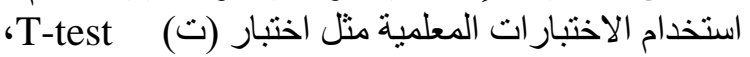

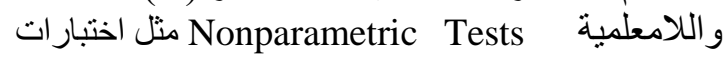

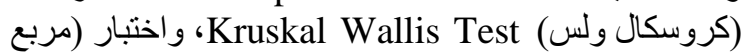

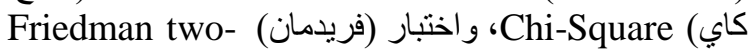
.way analysis of variance by ranks

وتم استخدام أسلوب نسبة الإشباع من الحاجات

الأساسية لقياس مستوى الفجوة التعليمبة لسكان البنادية النادية

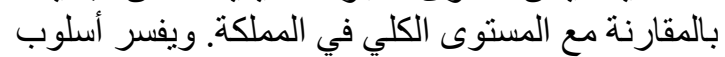

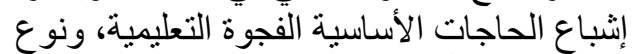

الحرمان، وفقاً للمعادلة التالية (Hunaiti, 2006):

$E G=\frac{B B}{B G L}-100 \%$

$$
\text { حيث أن: }
$$

EG

BB البادية في حال كونه معيار إيجابي مثل معدل المئل الانتظام

$$
\text { و المسنوى التعليمي. }
$$

BGL

وفي حال قياس الفجوة لمعيار الأمية يكون المقئون المياس

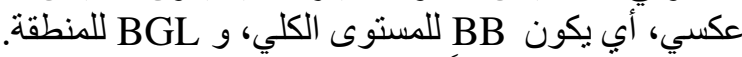

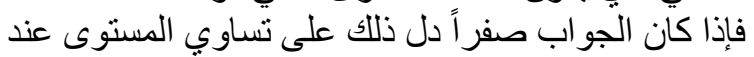

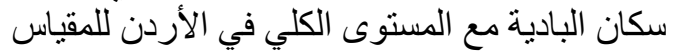

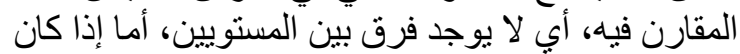

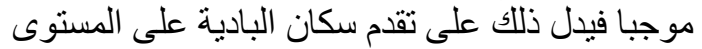

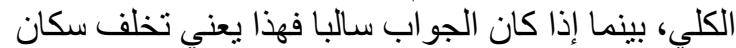
البادية بالمقارنة مع المسنوى الجني.

\section{3ناقشة نتائج الاراسة \\ 1-3-3 المؤشرات التعليمية: نوع المدرسة}

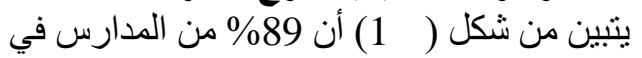

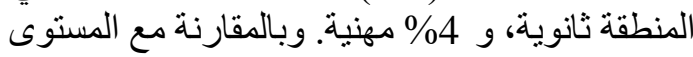
الكلي في المملكة، فقد بلغت نسبة المدارس الثنانوية فيه المبله

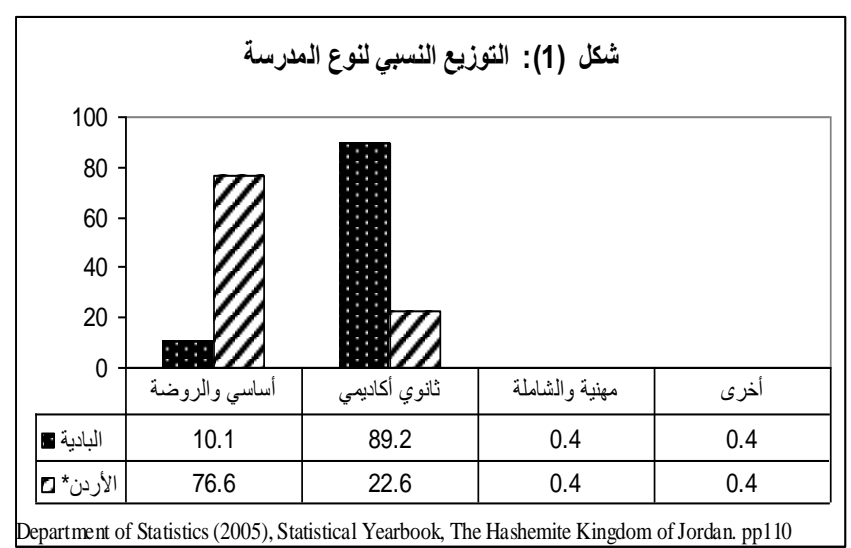


منطقة الدر اسة. ويلاحظ من الخط المتعرج في الثكل ( 5)

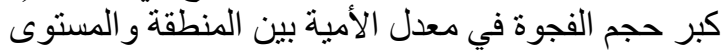

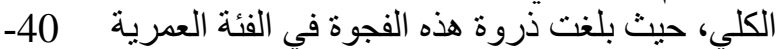

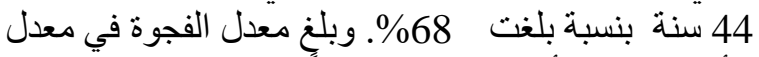

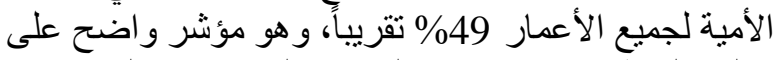

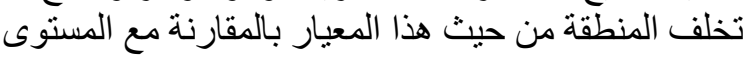
الكلي. و هذه النتيجة تؤكد على ما توصن التئل إليه الحنيطي

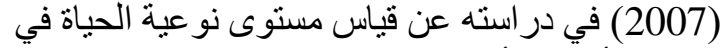

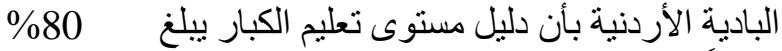

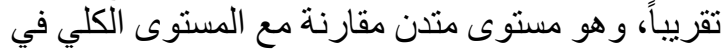
المملكة الذي بلغ 89\% (UNDP, 2005).

\section{الههف الرابع: أسباب ارتفاع نسبة الأمية وعلاقتها بالنوع

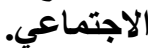

توصل المسح الميداني المصاحب للتعداد العادياد العام للسكان

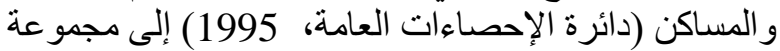

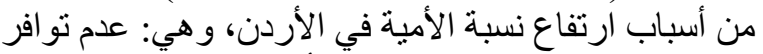

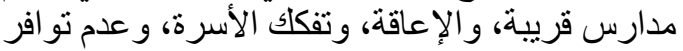

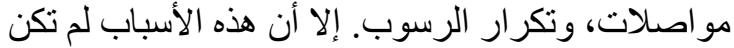

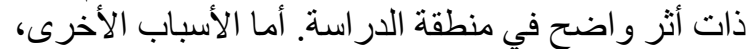

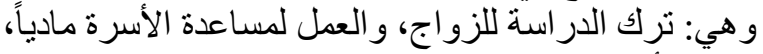

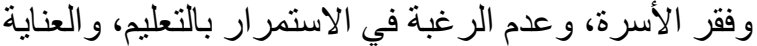
بأفر اد الأسرة، و لأسباب أخرى، فكانت ذان ذات علاقة بأسباب الأسباب الأمية في منطقة الدر اسة.

Friedman توصل تحليل اختبار (فريدمان)

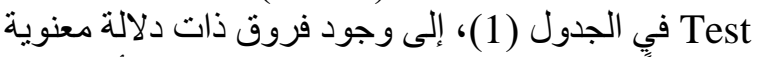

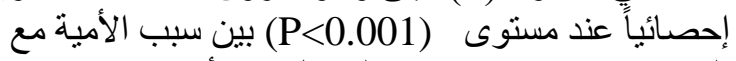

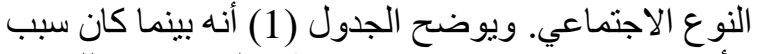

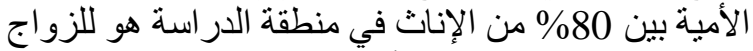

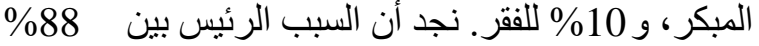
من الذكور كان العمل و العناية بمصالح الأسرة. و هذه العنه

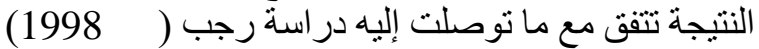

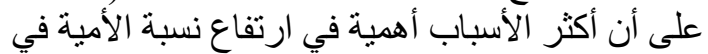
البادية الأردنية، وخاصة بين الإناثة، يرجية الإنعاع إلى أسباب

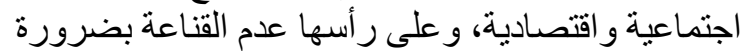

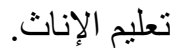

\begin{tabular}{|c|c|c|c|}
\hline عينة الاراسة & $\begin{array}{l}\text { إناث } \\
\%\end{array}$ & $\begin{array}{l}\text { ذكور } \\
\%\end{array}$ & سبب الأمية \\
\hline 4.2 & 5.0 & 2.1 & أعمال المنزل \\
\hline 9.6 & 10.1 & 8.5 & الفقز \\
\hline 27.1 & 3.4 & 87.2 & العمل ومصالح الأسرة \\
\hline 0.6 & 0.0 & 2.1 & الإعاقة \\
\hline 57.2 & 79.8 & 0.0 & الزواج \\
\hline 1.2 & 1.7 & 0.0 & أخرى \\
\hline 100.0 & 100.0 & 100.0 & المجموع \\
\hline \multicolumn{3}{|c|}{$\chi^{2}=160.0, d f=1$, P-value $<0.001$} & $\begin{array}{l}\text { نتائج تحليل اختبار } \\
\text { Friedman Test }\end{array}$ \\
\hline
\end{tabular}

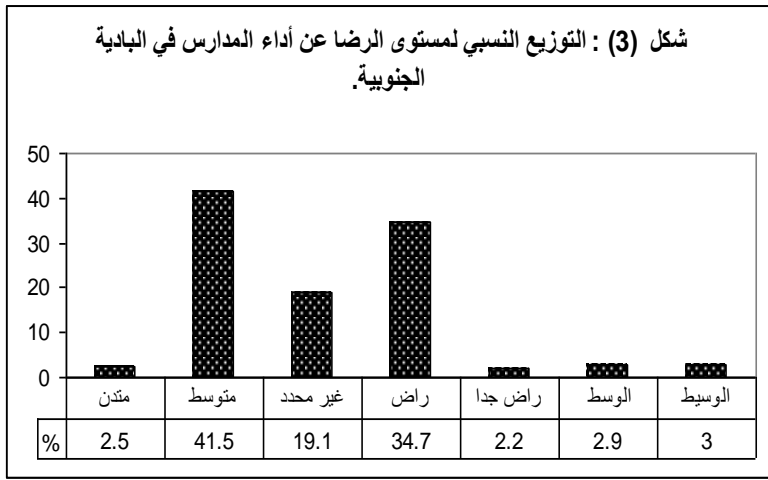

الههف الثالث: قياس الفجوة التعليمية لمستوى الأمية. يبين شكل ( 4) أن نسبة الأمية للذين أعمار هم 15

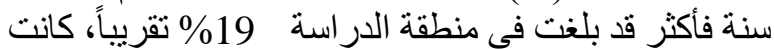

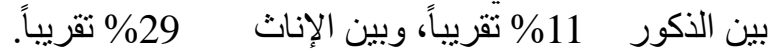

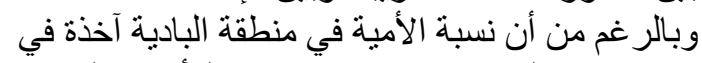

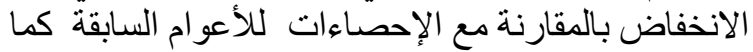

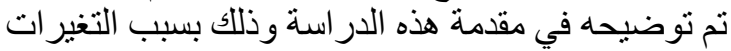

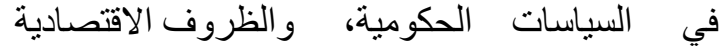

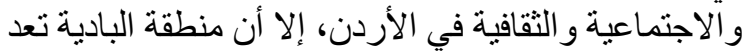

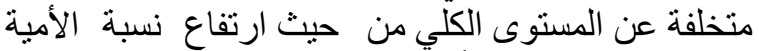

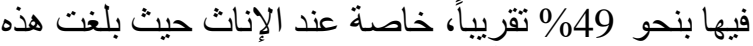

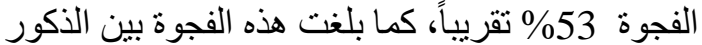

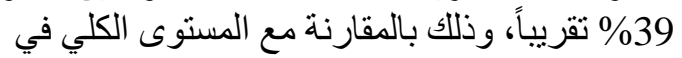

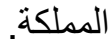

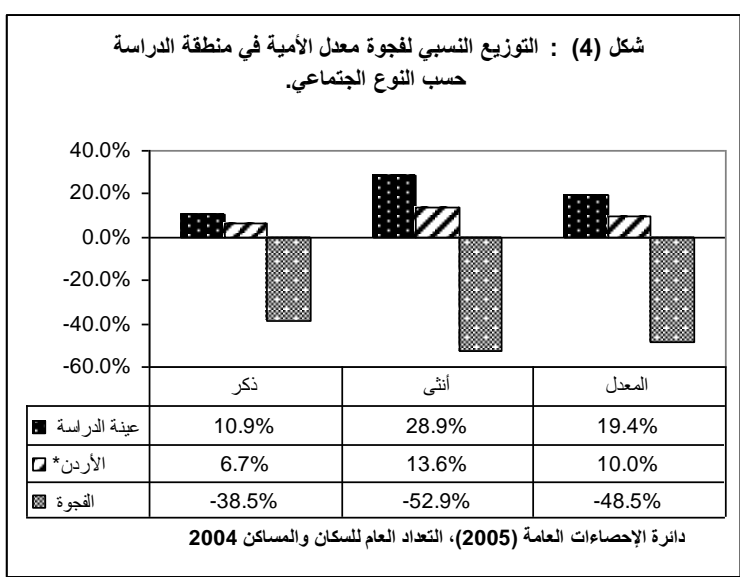

تابع الهدف الثالث: قياس الفجوة التعليمية لمستوى الأمية، حسب الفئات العمرية.

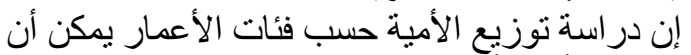

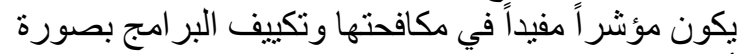
أفضل في معالجة هذه الظاهرة الاجتماعية.

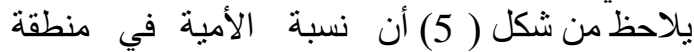

الدر اسة تزداد بشكل ملحوظ من عمر 40 سنة فئة فأكثر ،

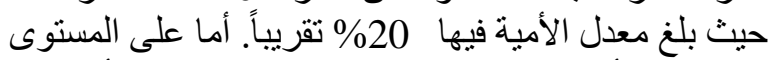

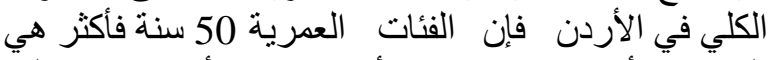

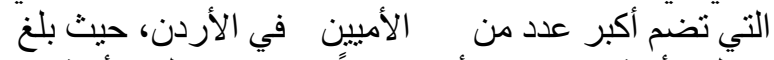
معدل الأمية فيها 10\% أي تقريباً نصف معدل الأمية في 


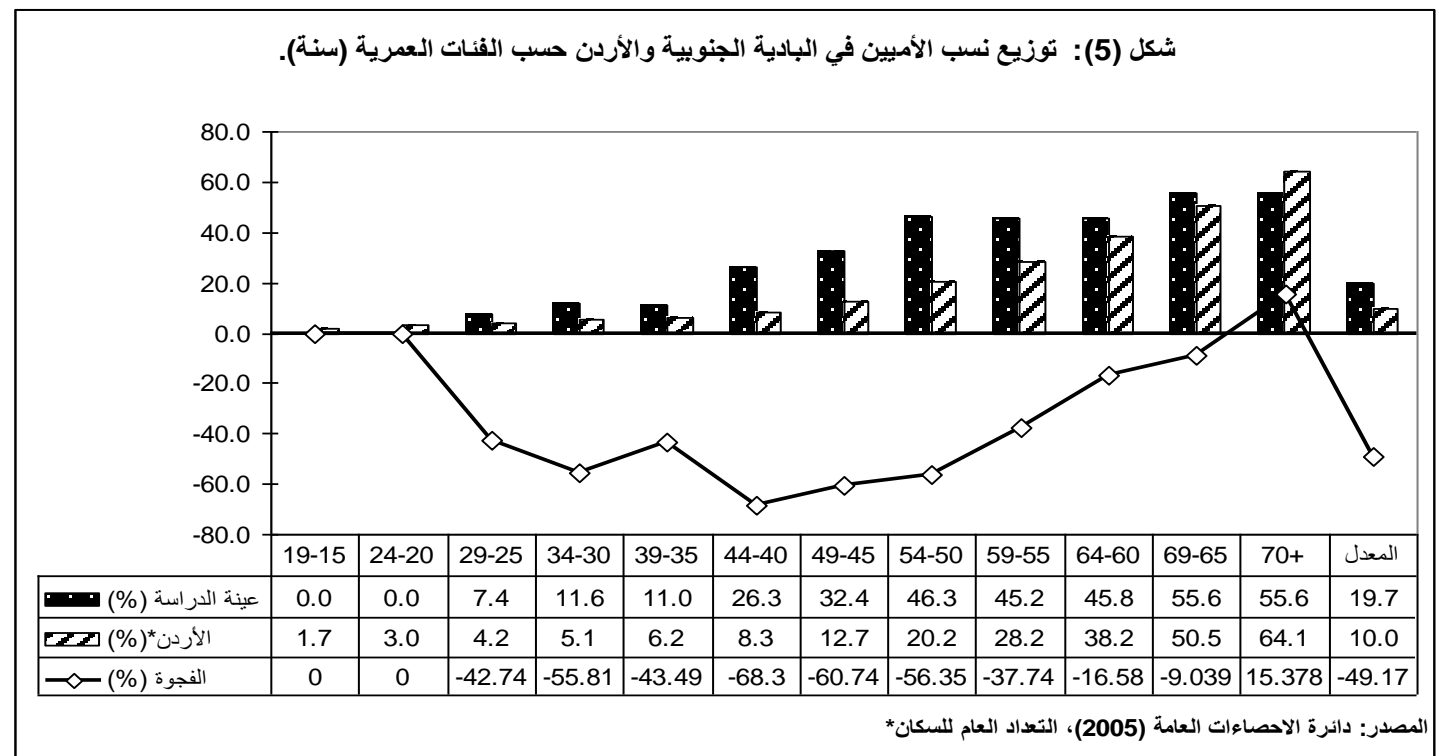

أن منطقة الدر اسة تتفوق على المستوى العام في هذا

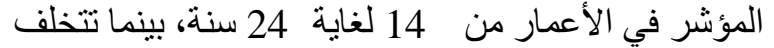

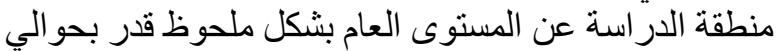
39\% في مجال الانتظام للأعمال من 25 و وحتى العنى 29 سنة و هي فئة أعمار الذين من المنوقع أن ينتظموا في الدراس واستات العليا.

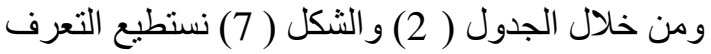

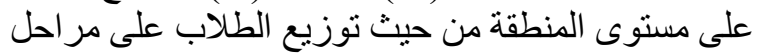

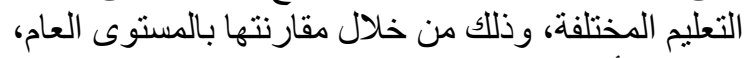

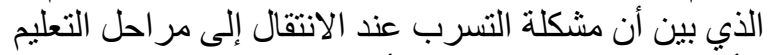

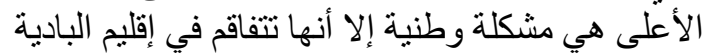

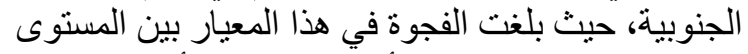

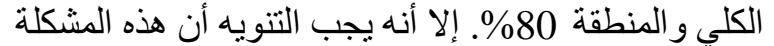

تتفاقم عند الإناث أكثر من الذكور خاصة في منطة التهقة

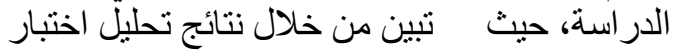
(Kruskal Wallis Test) ذات دلالة معنوية إحصائياً (P<0.01) بين معدل الانتظام

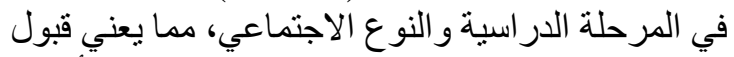

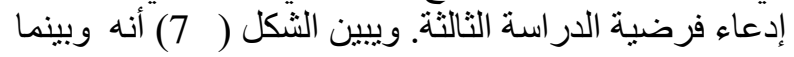

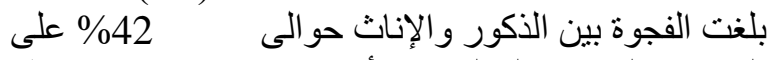

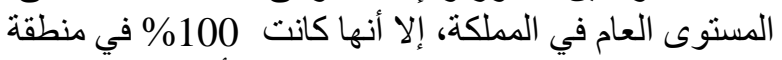
الدراسة، و هذا مؤشر على على عدم تمكين المر أة وتخلفها في هذا المعيار مقارنة مع الذكور في منطقة الدر استة الدئ. الهذف السادس: التعرف على أسباب عدم الإنتظة الإم في الار اسة، حسب النوع الاجنة الاجتماعي.

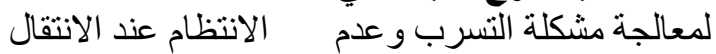

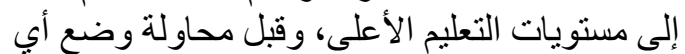

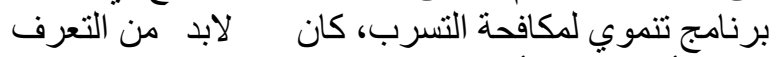

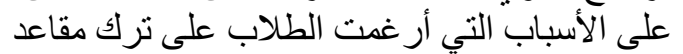

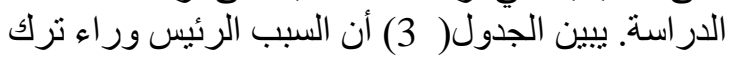

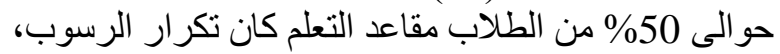

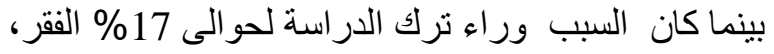

الهدف الخامس: قياس الفجوة التعليمية لمعدل الانتظام في الدراسة، حسب النوع الاجتماعي، المرحلة التقليمية.

يُّينين من خلال شكل ( 6)، أن نسبة أعداد المنتظمين

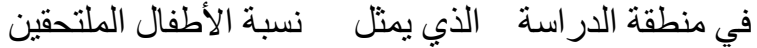

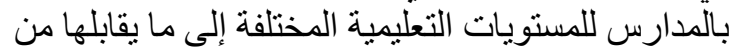

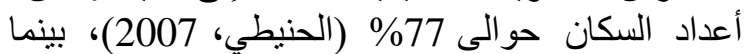

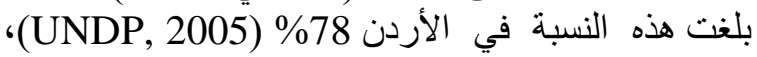

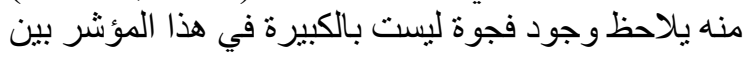

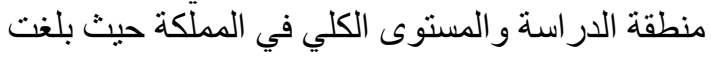

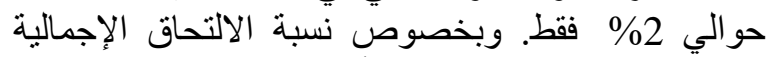

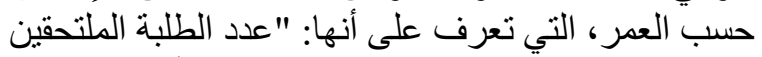

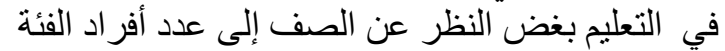

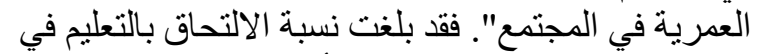

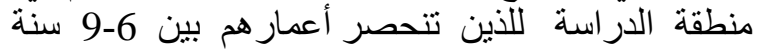

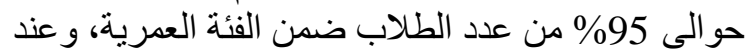

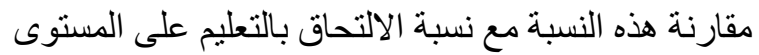

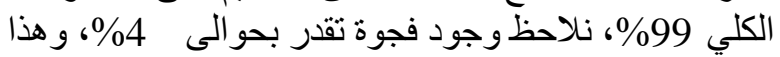

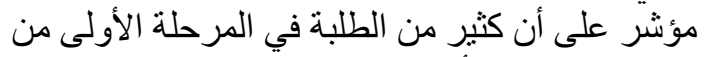

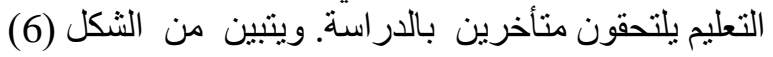

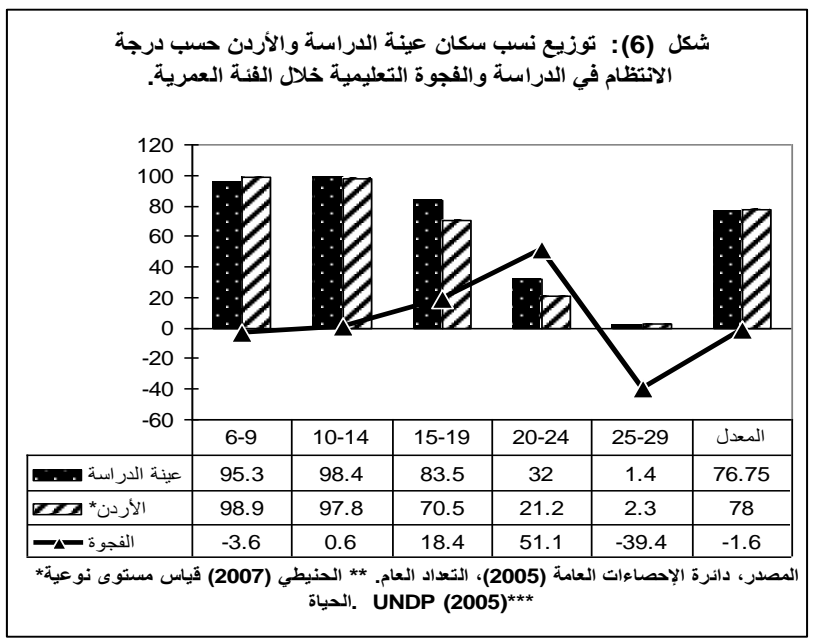


الهُف السابع: قياس الفجوة في المستوى التعليمي، حسب النوع الاجتماعي.

بينت نتائج ألمسح الميداني للذين أعمار هم 15 سنة فأكثر

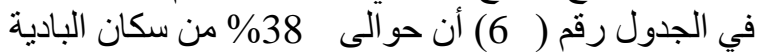

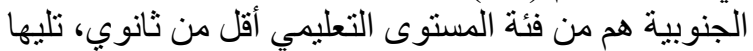

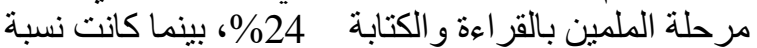

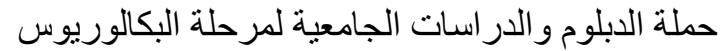
فأعلى لا تتجاوز 6. \% \%. و على المستوى الكلي في المملكة

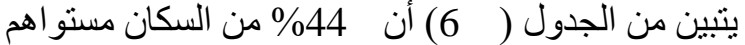

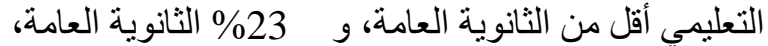

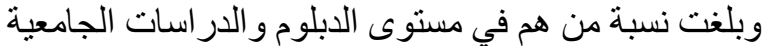
لمرحلة البكالوريوس فأعلى حو الى 20\% وبمقارنة منطقة الدر اسة مع المستوى الكلي في المملكة

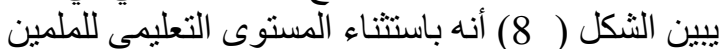

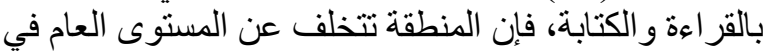

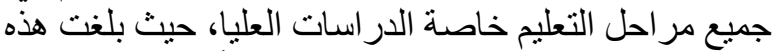

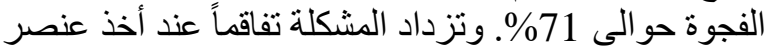

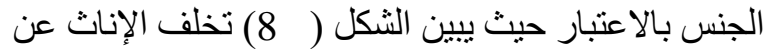

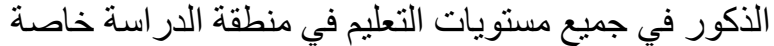

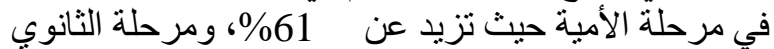

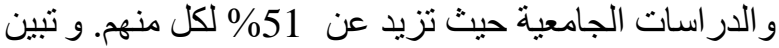
من خلال نتائج تحليل اختبار ( Kruskal Wallis Test)

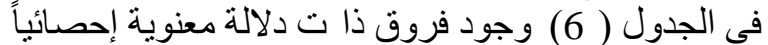

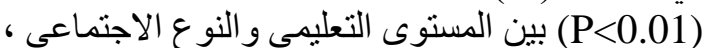
و عليه لا يمكن رفض الفرضية الخامسة. 2-2-3 التوصيات

نلاحظ من خلال عرض نتائج هذه الدر اسة أنه

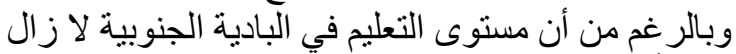

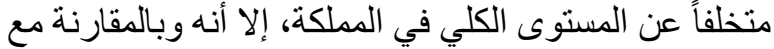
التعدادات السنوية السابقة فإن مستوى التعليم في البادية بدأ

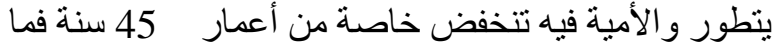

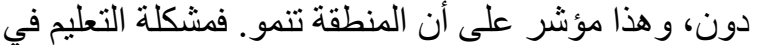
البادية الأردنية لا تكمن في شح البن البنية التحتية للخدمات التئية

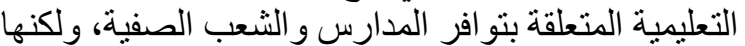

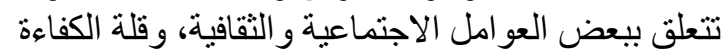

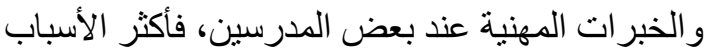

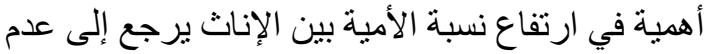

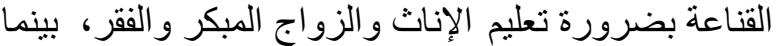

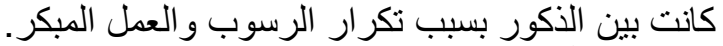

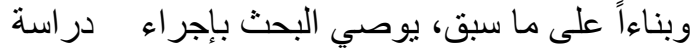

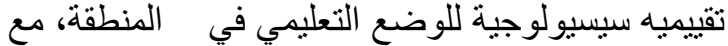

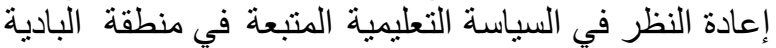

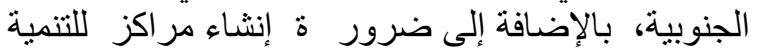

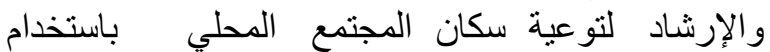
أسلوب المشاركة الثعبية في التخطيط و التنفيذ

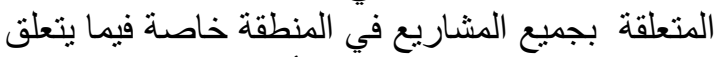

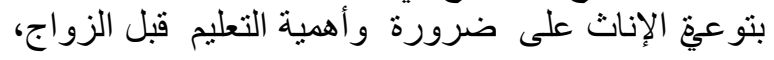

\begin{tabular}{|c|c|c|c|c|}
\hline \multicolumn{5}{|c|}{ شكل رقم (7) : الفجوة في معل الاتظظام حسب المرحلة الاراسية } \\
\hline \multirow{2}{*}{$\left.\begin{array}{r}100.0 \\
0.0 \\
-100.0 \\
-200.0\end{array}\right]$} & \multicolumn{3}{|c|}{$D$} & $\because 17$ \\
\hline & الأساسي & 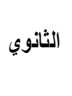 & بكالوريوس & | لدراسات عليا \\
\hline بين الدكور والإناث في منطقة إل & -8.0 & -18.2 & -31.9 & -100.0 \\
\hline بين الاكور والاناث افي لأردن & -4.9 & -7.5 & 9.4 & -42.1 \\
\hline بين منطقة الدراسة والمستوى D & 25.9 & 56.3 & -28.2 & -80.0 \\
\hline & & التعاد العا. & كات العامة (المدر & ** * دائرة الإحص \\
\hline
\end{tabular}

ولحو الى 16\% للعمل، ولحو الى 12\% للزو اج. ومنه يتبين

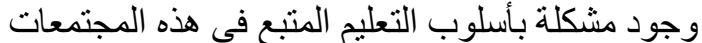

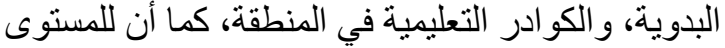

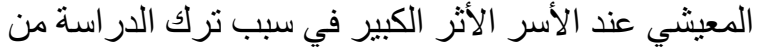

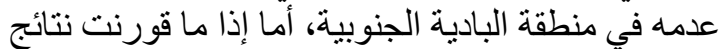
الجدولين (3)، و (4) ، بين مستوى البادية و المستوى الكلى الجيلي في المملكة نلاحظ أن سبب فقر الأسرة بعتبر عاملاً أساسياً

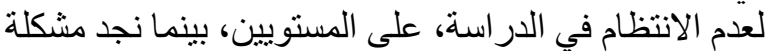
تكر ار الرسوب ومثكلة الزواج و واضحتين في منطقة البادية أكثر من المستوى الكلي في المملكة. ويبين الجدول ( 3) أن عمق المشكلة في عدم الانتظام

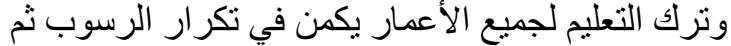

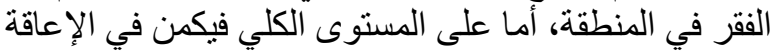

و عند أخذ جميع الأعمار من سن 15 سنة فأكثر بعين

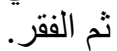

الاعتبار يبين الجدول ( 5) أن أكثر الأسباب وراء ترك الأن

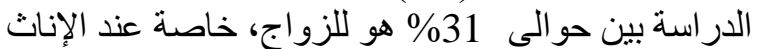

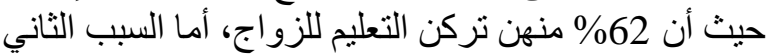

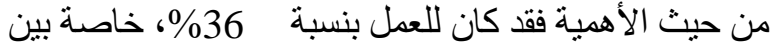

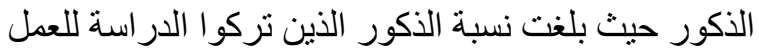
حوالى 65\% من العدد الكلي للذين تركو ا الدر اسة، ثم كان النئ

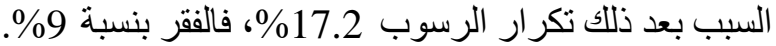
أما على المستوى الكلي في المملكة فإن السبب الرئيس يكمن

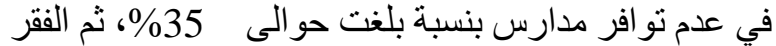

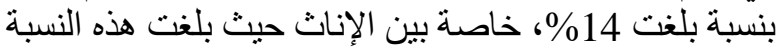
حوالى 23\%. وتنين من خلال نتائج تحليل اختبار (مربع الإن

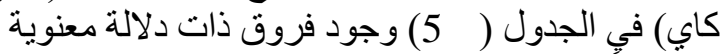

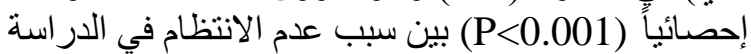

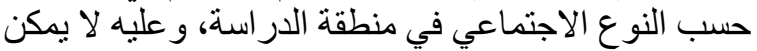
رفض فرضية الدر اسة الر ابعة. 
2): توزيع نسب الطلاب حسب مرحلة الانتظام و الجنس (1966) (196)

\begin{tabular}{|c|c|c|c|c|c|c|c|c|c|}
\hline \multicolumn{3}{|c|}{ الأردن (2005) ** } & \multicolumn{3}{|c|}{ در اسة التخطيط (1996)* } & \multicolumn{3}{|c|}{ عينة الدراسة (2005) } & المنطقة \\
\hline المتوسط العام & أنثى & ذكر & المتوسط العام & أنثى & ذكر & العام & أنثى & ذكر & مرحلة الانتظام \\
\hline 75.7 & 36.9 & 38.8 & 86.4 & 40 & 46.4 & 95.3 & 34.5 & 37.5 & الأساسي \\
\hline 12.8 & 6.2 & 6.7 & 10.6 & 4.7 & 5.9 & 20 & 9 & 11 & الثانوي \\
\hline 11.0 & 5.8 & 5.3 & 3 & 1.7 & 1.3 & 7.9 & 3.2 & 4.7 & بكالوريوس ودبلوم \\
\hline 0.5 & 0.11 & 0.19 & 0 & 0 & 0 & 0.1 & 0 & 0.1 & در اسات عليا \\
\hline 100 & 49 & 51 & 100 & 46.3 & 53.7 & 100 & 46.7 & 53.3 & المجموع \\
\hline
\end{tabular}
value $<0.01$

(Wallis Test

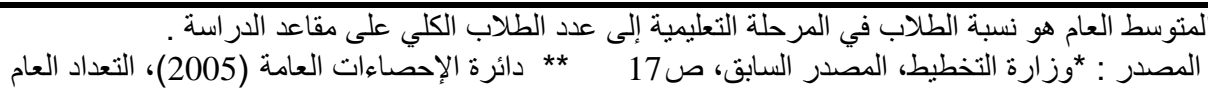

جدول (3): التوزيع النسيي لأهمبة سبب عدم الانتظام الرئبس في كل فئة عمرية للسكان غير المرنظمين الذين أعمار هم 6-24 سنة.

\begin{tabular}{|c|c|c|c|c|c|}
\hline \multicolumn{6}{|c|}{ الفئة العمرية } \\
\hline المجموع & $24-20$ & $19-15$ & 14-10 & $9-6$ & السبب - ال \\
\hline 49.5 & 32.6 & 15.9 & 0.5 & 0.5 & تكرار الرسوب \\
\hline 16.8 & 12.5 & 3.3 & 0.5 & 0.5 & الفقر | (الفر \\
\hline 15.8 & 10.6 & 3.3 & & & للعمل ومصالح الأسرة \\
\hline 11.1 & 9.6 & 1.0 & 0.5 & & لللزواج \\
\hline 0.5 & 0.5 & & & & أعمال المنزل \\
\hline 1.0 & & & 1.0 & & الإعاقة \\
\hline 3.3 & 2.8 & 0.5 & & & أخرى \\
\hline 2.0 & 1.5 & 0.5 & & & غير مبين \\
\hline
\end{tabular}

جدول (4): التوزيع النسيي لسبب عدم الانتظام لكل فئة عمرية للسكان غير المرنظمين الذين أعمار هم 6-24 سنة.

\begin{tabular}{|c|c|c|c|c|c|c|c|c|}
\hline \multicolumn{4}{|c|}{ الأردنن* } & \multicolumn{4}{|c|}{ عينة الدراسة } & المنطقة \\
\hline $24-20$ & $19-15$ & $14-10$ & $9-6$ & $24-20$ & $19-15$ & $\overline{14-10}$ & $9-6$ & الفئة العمرية \\
\hline & & & & & & & & السبب \\
\hline 0.5 & & & & 45 & 64.7 & 20 & 50 & تكرار الرسوب \\
\hline 1.6 & 17 & 12 & 0.4 & 17.2 & 13.7 & 20 & 50 & الفقر \\
\hline 28 & 8.4 & & 0.2 & 17.2 & 13.7 & & & للعمل ومصالح الأسرة \\
\hline 2 & 4.2 & & & 3.3 & 7.8 & & & \\
\hline 2.6 & 6 & 1.3 & 0.7 & 1.4 & & & & أعمال المنزل \\
\hline 4.7 & 38.1 & 62.7 & 2.3 & $\overline{0}$ & & 40 & & الإعاقة \\
\hline 19.2 & 26.3 & 18.7 & 3.5 & 4 & 2 & & & أخرى \\
\hline 32.6 & & & 3.9 & 2 & 2 & & & غبر مبين \\
\hline 1 & 4.2 & 5.3 & 0.32 & 0 & & & & عدم تو افر مدرسة \\
\hline 7.8 & & & 0.28 & 0 & & & & تفكلك الأسرة \\
\hline
\end{tabular}


جدول (5): توزيع نسب غير المنظمين للأعمار 15 سنة فأكثر، حسب السبب، والجنس.

\begin{tabular}{|c|c|c|c|c|c|c|}
\hline \multicolumn{3}{|c|}{ الأردنث* } & \multicolumn{3}{|c|}{ عينة الدراسة } & \multirow{2}{*}{ النوع الاجتماعي } \\
\hline المعدل العام & إناث & ذكور & المعدل العام & إناث & ذكور & \\
\hline 0.1 & & 0.1 & 17.2 & 12.2 & 22 & تكرار الرسوب \\
\hline 14.2 & 10 & 22.5 & 9.4 & 11.3 & 7.6 & الفقز \\
\hline 7.9 & 3.7 & 15.3 & 35.6 & 5.8 & 64.5 & للعمل ومصالح الأسرة \\
\hline 0.6 & 0.9 & - & 30.7 & 62.3 & 0.2 & لللزواج \\
\hline 9.4 & 13.5 & 0.7 & 1.8 & 3.4 & 0.2 & أعمال المنزل \\
\hline 2.6 & 1.5 & 5 & 0.5 & 0.2 & 0.7 & الإعاقة \\
\hline 0.1 & 0.3 & 0.1 & 2.9 & 3 & 2.9 & غير مبين \\
\hline 34.9 & 34.2 & 36 & 0.5 & 0.7 & 0.2 & عدم توافر مدرسة \\
\hline 0.6 & 0.7 & 0.7 & & & & تفكلك الأسرة \\
\hline 0.03 & & 0.1 & & & & صعوبة المنهاج \\
\hline 29.6 & 35.2 & 19.5 & 1.4 & 1.1 & 1.7 & أخرى \\
\hline
\end{tabular}

\begin{tabular}{|c|c|c|c|c|c|c|}
\hline & \multirow{2}{*}{ الأردنث } & & \multicolumn{3}{|c|}{ البادية الجنوبية } & \multirow{2}{*}{ 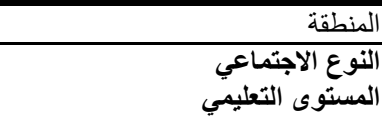 } \\
\hline المعدل العام & & ذأكور & المعدل العام & إناث & ذكور & \\
\hline 10.0 & 13.5 & 5.1 & 19.7 & 28.2 & 10.9 & 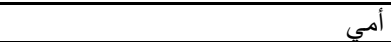 \\
\hline 3.3 & 3.1 & 3.5 & 24.2 & 23.1 & 25.9 & ملم \\
\hline 44.0 & 39.6 & 48.3 & 38.1 & 36.8 & 40.0 & أقل من ثانوي \\
\hline 23.6 & 24.2 & 23.2 & 9.1 & 5.8 & 12.3 & 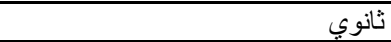 \\
\hline 8.9 & 10.8 & 7.0 & 2.5 & 1.9 & 3.2 & دبلوم متوسط \\
\hline 10.9 & 8.8 & 12.9 & 3.2 & 2.1 & 4.3 & بكالوريوس ودر اسات عليا \\
\hline \multirow[t]{2}{*}{0.1} & 0.1 & 0.1 & 2.8 & 2.1 & 3.4 & غير مبين \\
\hline & & & $\chi^{2}=9.2$, & $1, \mathrm{P}$ & $<0.01$ & نتائج اختبار Kruskal Wallis Test \\
\hline
\end{tabular}

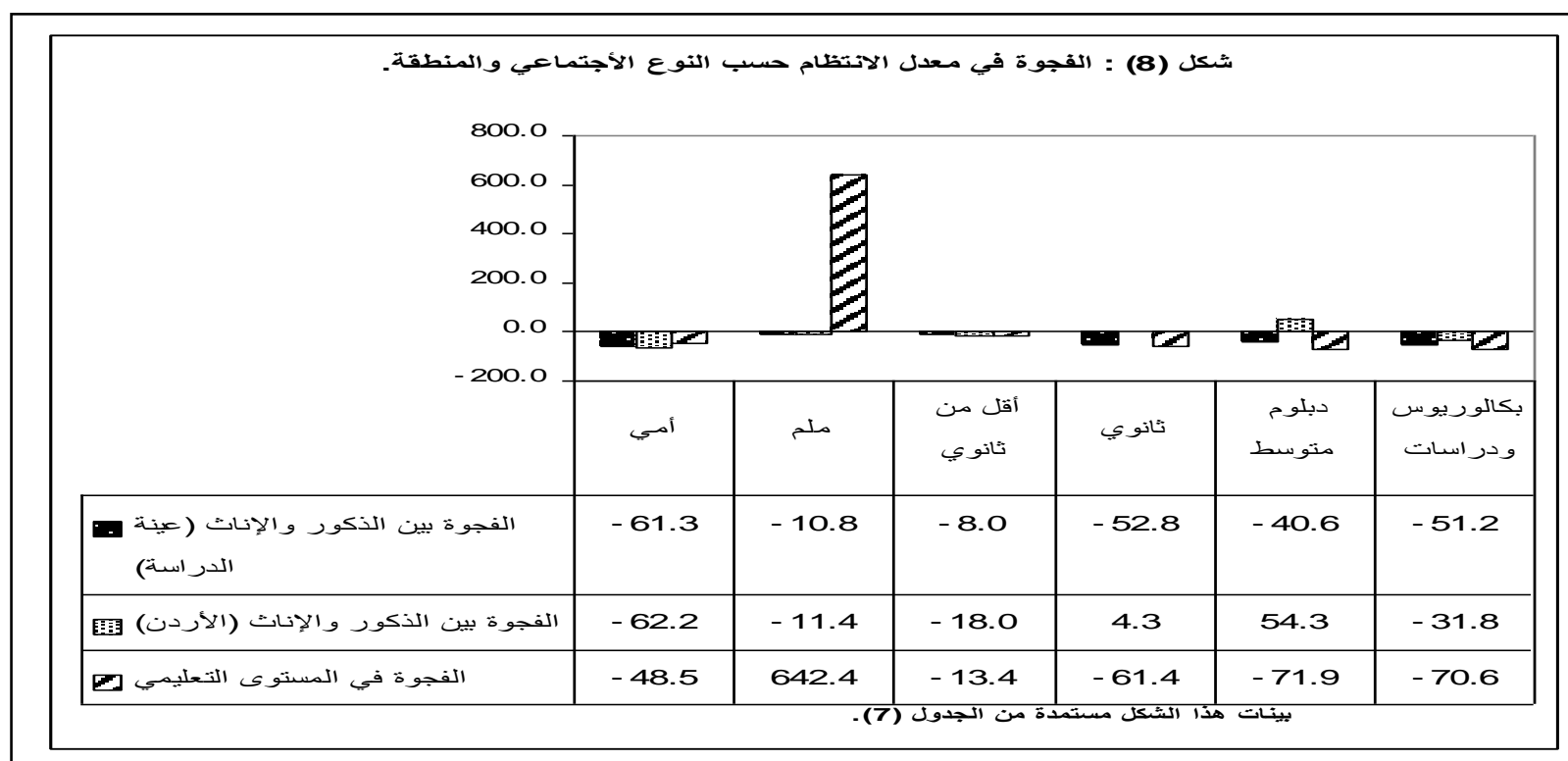




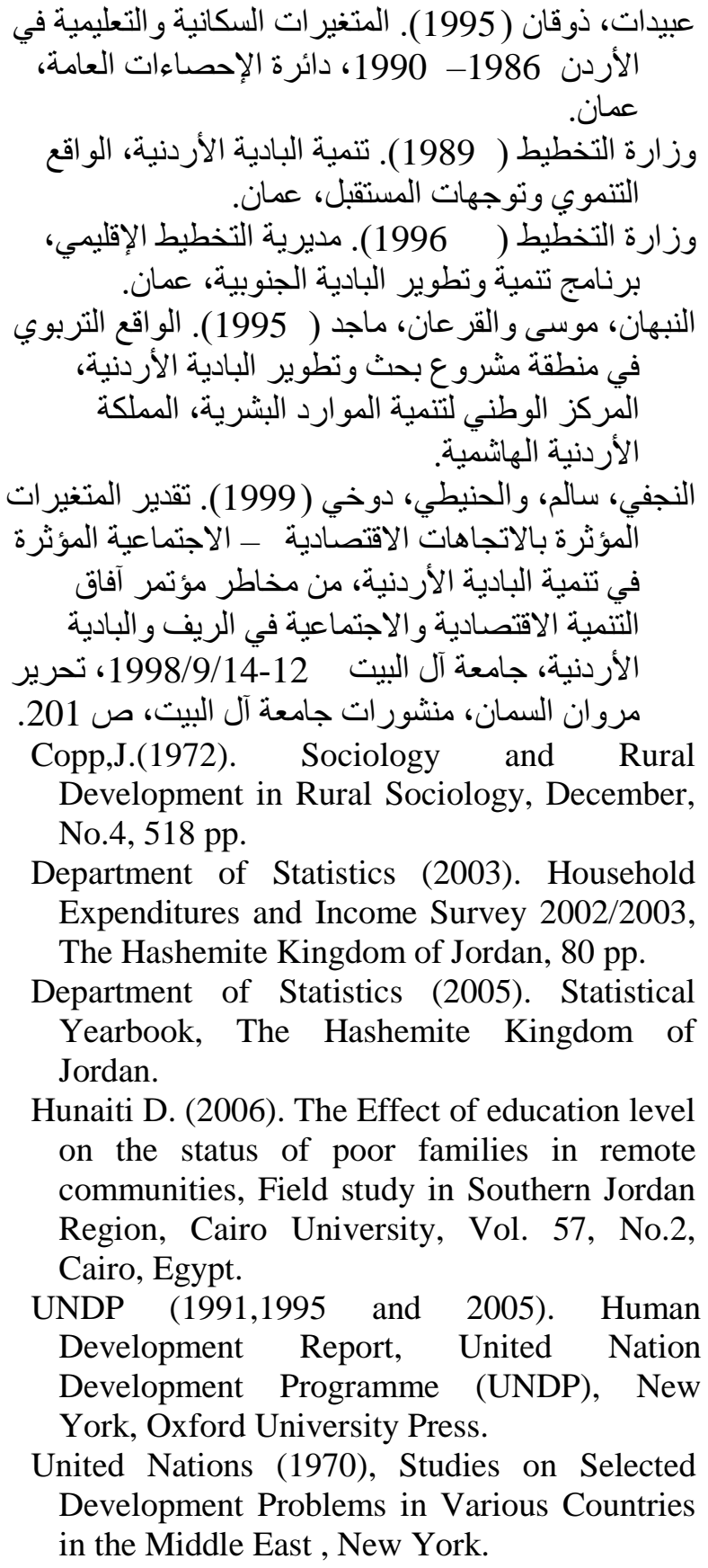

Department of Statistics (2003). Household Expenditures and Income Survey 2002/2003, The Hashemite Kingdom of Jordan, 80 pp.

Department of Statistics (2005). Statistical Yearbook, The Hashemite Kingdom of Jordan.

Hunaiti D. (2006). The Effect of education level on the status of poor families in remote communities, Field study in Southern Jordan Region, Cairo University, Vol. 57, No.2, Cairo, Egypt.

UNDP (1991,1995 and 2005). Human Development Report, United Nation Development Programme (UNDP), New York, Oxford University Press.

United Nations (1970), Studies on Selected Development Problems in Various Countries in the Middle East, New York.

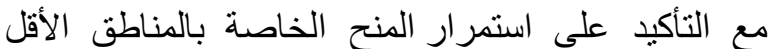

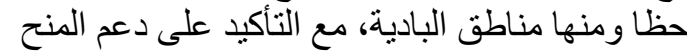

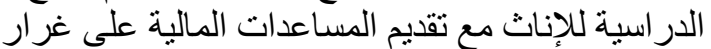
المكرمة الملكية لأبناء القوات المسلحة المبات والأمن العام.

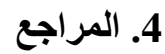

التل، أحمد يوسف (1989)، تطوير نظام التعليم في الأردن

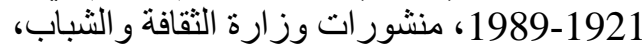

عمان.

الحنيطي، دوخي ( 1997). الاتجاهات الاقتصادية

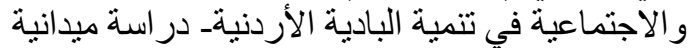

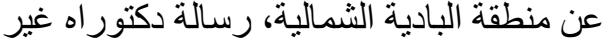
منشورة، جامعة الموصل، العراقة

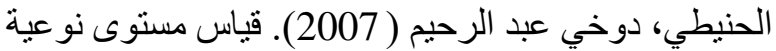

الحياة في إقليم البادية الأردنية (در اسة ميدانية لمنطقة

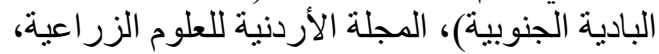

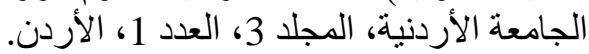

دائرة الإحصاءات العامة ( 1962). التعداد العام للسكان

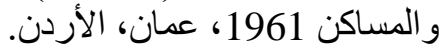

دائرة الإحصاءات العامة ( 1980). التعداد العان العام للسكان

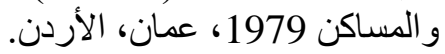

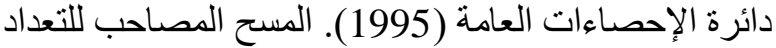

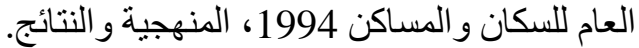
دائرة الإحصاءات العامة ( 2005). التعداد العام للسكان و المساكن 2004، 2004، المنهجية والنتائج النهائية،

http://www.dos.gov.jo/dos_home_a/main/ind ex.htm رجب، عادل ( 1998). برنامج محو الأمية وتتمية الموارد

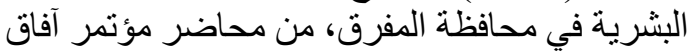

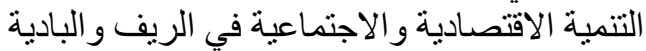

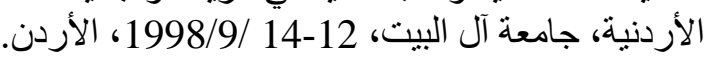

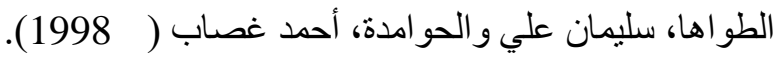

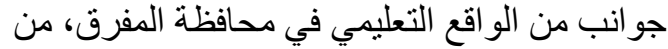

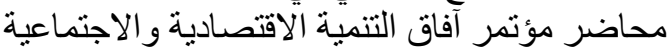

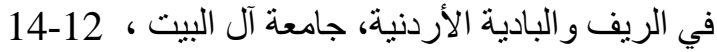

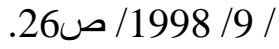

